\title{
Development and Print of Clothing through Digitalized Designs of Natural Patterns with Flexible Filaments in 3D Printers
}

\author{
Jean Roger Farfán Gavancho ${ }^{1}$, Wilber Antonio Figueroa Quispe ${ }^{2}$, Dayvis Victor Farfán Gavancho ${ }^{3}$ \\ Beto Puma Huamán ${ }^{4}$, Victor Manuel Lima Condori ${ }^{5}$, George Jhonatan Cahuana Alca ${ }^{6}$ \\ Universidad Nacional de Juliaca, ${ }^{1,2,4,5,6}$ \\ Instituto Superior Tecnológico Manuel Núñez Butrón ${ }^{3}$
}

\begin{abstract}
This study proposes clothing development by digitalizing natural patterns with flexible filaments in 3D printers. The motivation to carry out this research was the similarity and evenness features of fractals. For this purpose, three natural exemplars have been selected and subsequently digitized: Snowflake, Honeycomb, and Flower of Life, with line variants and infill density at $12 \%$. The garment was printed with Thermoplastic polyurethane (TPU) and Thermoplastic Elastomer (TPE) in two 3D printers: Anet A8 and M3D Crane Quad. Lastly, the combination of filaments, printers, line variant, and infill density resulted in forty-eight (48) samples. Two tests were carried out on the printed patterns for the research: The elongation and tensile strength test. The elongation test consists of applying a variable force to each exemplar in order to obtain the percentage of its elastic limit before reaching its fracture point. The tensile test applies a variable vertical power to each design to determine how it will behave under particular pressure. Results show that the snowflake pattern with line variant obtained the best performance in the elongation test compared to the tensile test. Subsequently, four clothing samples were printed with TPU and TPE materials on the two printers mentioned above. The garments are composed of twenty-nine (29) pieces respectively which were connected with a $3 D$ pen. Finally, the item of clothing was worn by five volunteers of different sizes, as shown in the following pages.
\end{abstract}

Keywords-Natural pattern; fractal; garment; digital design; flexible filament; $3 D$ printing

\section{INTRODUCTION}

Technology advances fast, impacting directly on different industry sectors, such as the Textile Industry. Stereo lithography (S.L.) is an example of this, and it refers to converting 3D data to physical products using 3D printing [1]. $3 \mathrm{D}$ modeling is the process of digitalizing an image that the user previously shaped.

On the other hand, with the rise of digital manufacturing, new terms appear; for example, Computer Assisted Manufacturing (CAM), Computer-aided Design (CAD), and Computer-aided Engineering (CAE). Thus there is the convergence of control machines and computer science, transforming fields such as aerospace, naval, and textile industry [2].
It is important to use the fractal theory for the designs of natural patterns that have order and complex geometry of nature since it allows to create and homogenize new base patterns with line and subsequently elaboration of garments. This emphasizes the factors of creativity, the dynamism of the geometric pattern, similarity, and repetition, which are characteristics of human fractals [3]. Furthermore, it helps to the innovation of digitalized designs of natural patterns for their application in garments in the textile industry.

Elements such as the design and basic pattern, digital manufacturing, and 3-D printing make new production processes possible, for example, creating garments and footwear. Danit Peleg is a pioneer in making garments from flexible filament materials in 3D printers[4].

The development of garments from natural snowflake patterns printed in 3D means a new production process, which also creates the challenge of product customization. Besides, the growth of concepts such as Industry 4.0 will allow the user to place an order and print it in a FabLab center [5].

The National University of Juliaca (UNAJ) is an academic institution that promotes research. The Faculty of Textile and Apparel Engineering of UNAJ generates new knowledge through study lines such as "Production processes, design, safety and quality in the Textile and Apparel Industry," [6], which aims to experiment and explore the process of digital manufacturing and 3D printing. Some factors that arise from this research line are cost, time, quality, comfort, resistance, and adaptability.

On the other hand, the investigation leads to generating new lines of research in Textile Engineering, following the improvements of digitized technology, Industry 4.0, and product customization related to garments and footwear. For example, developing new ideas with 3D scanners and software of footwear with padding, analyzing resistance, flexibility, elongation, and doubles in the textile industry. In the same way, analyzing the acceptance and appreciation of the garment and footwear with filaments in 3D printers in potential users at 38000 meters above sea level. There is also the opportunity of examining the adhesion of filaments to products made of alpaca fiber and sheep wool as an added value to innovative fashion in the Textile Industry. 


\section{RELATED WORKS}

For his undergraduate dissertation, [7] printed a garment with a home 3D printer, demonstrating that this technology could be accessible to anyone interested in developing 3D printing. Peleg [6] was inspired by the work of Eugene Delacroix in "Liberty Leading the People," for which she adapted triangular geometric figures as a primary natural pattern and subsequently printed with biopolymer polylactic acid (PLA) and soft PLA.

In [8], several pieces of clothing were printed using Filaflex filament (a variant of TPE), which is differentiated by its flexible nature. Her work consisted of five garments that stand out the mesostructured cellular pattern proposed by Andreas Bastian, characterized by the hexagonal geometric figure.

In [1], [9] produced a 3D printed garment using the natural pattern of Brain coral, which is defined by a hexagonal geometric figure. The design was digitalized with Rhinoceros and Grasshopper software to create the surface of such clothes. Additionally, the author used PLA, ABS (Acrylonitrile Butadiene Styrene), and Filaflex filaments to perform bending tensile tests and determine the most suitable material for developing the garment.

In [10], Research on garment pattern design based on fractal graphics, scholars generated graphics using two types of fractals: floral graphics and artistic geometric graphics, subsequently applied to the garment. The leading software was MATLAB, supported by Adobe Photoshop. The fractal patterns were applied on silk scarves with digital printing technology. It generates complex and new designs through creativity

In [11], A study on fractal patterns for the textile design of the fashion design; drawings were made based on Julia sets pattern and algorithms. This new methodology generates designs for the Textile Industry. The software used to create the algorithms was JAVA, allowing to generate new and complex designs that traditionally could not be drawn.

In [12], authors made tensile and elongation tests on six PLA-based filaments with some additive materials for 3D printing. The tests printed specimens with $100 \%$ filling and with dimensions of $115 \mathrm{~mm}$ x $20 \mathrm{~mm}$ and $4 \mathrm{~mm}$ thickness were included. The printer used was Cetus MKII and an Instron 5566 Universal Testing Machine. Specimen specifications are set up according to ISO 3167 1994. The filament that obtained the best performance in the tensile test was PLA additive with metal obtaining $121.36 \mathrm{~N}$. and the elongation test with PLA technical additive filament with $20.16 \%$.

In [13], Determination of elastic properties of polymeric pieces constructed by 3D printing, subjected to bending; authors analyzed the elastic properties (elongation) of PLA, Nylon, and HIPS filaments. Printed specimens were developed with $80 \mathrm{~mm}$ x $10 \mathrm{~mm}$ dimensions, a thickness of $4 \mathrm{~mm}$, and a percentage of filling at $100 \%$. The $3 \mathrm{D}$ printer model used was a Prusa Mendel M90. The novelty of this test is the angle of the infill line and the specimen wall with four combinations: $0^{\circ} / 0^{\circ}$ (long line infill), $45^{\circ} / 45^{\circ}$ (rhombic infill), $0^{\circ} / 90^{\circ}$ (squared infill), as well as the change of specimen position for vertical and horizontal printing. The $0^{\circ} / 0^{\circ}$ angle specimens obtained a better result with an average of more than 3\% elongation. The $0^{\circ} / 90^{\circ}$ angle vertically printed specimens performed better with an average of more than $3 \%$ almost as well as the $0 \% 0^{\circ}$ angle horizontally printed specimens.

In [14], the influence of infill parameter on the mechanical resistance in 3D printing, using the Fused Deposition Modeling method; the research objective was to determine the influence of infill on the tensile strength, tested under ABS filament. The printer used was a Makerbot Replicator 2X, and printed specimens with different filler percentages, starting from $0 \%$ to $5 \%$, were selected for this test. The standard test method applied was the ATSM D638-10 and the material tester utilized for the tensile test was a Gunt Hamburg WP 310 of $50 \mathrm{kN}$. The results obtained were: $34.57 \mathrm{MPa}$ with a percentage of filler at $100 \%$ and $14.62 \mathrm{Mpa}$ with a percentage of filler at $0 \%$. Therefore, the conclusion establishes that the higher the percentage of filler, the higher the tensile strength. However, for the manufacture of garments, the traction property must go along with the elongation feature.

In [15], Tensile strength of commercial polymer materials for fused filament fabrication 3D printing; the experiment was performed with three flexible filaments: NinjaFlex, Semiflex, and Nylon. Besides, standard filaments such as ABS, HIPS, Polycarbonate, and T-Glass were also utilized. The printed specimens had a $60 \mathrm{~mm} \times 13 \mathrm{~mm}$ dimension and a thickness of $3.2 \mathrm{~mm}$ using the ASTM D638 standard. The material tester was an INSTRON 4206 with a capacity of $10 \mathrm{kN}$ for rigid filaments and INSTRON 4210 for flexible filaments due to their higher elasticity compared with standard filaments. The conclusion states that standard filaments perform better in the tensile test than flexible filaments. Polycarbonate reached the highest value with $2041.64 \mathrm{~N}$, while Nylon reached a value of 1102.07 N. Lastly, NinjaFlex flexible filament was the lowest performer, as shown in its result: $161.88 \mathrm{~N}$.

\section{THEORETICAL BACKGROUND}

\section{A. Fractals}

In 1975, Benoit Mandelbrot first introduced the word "fractal," derived from the Latin term "fractus" [16]. Two meanings are attributed to this term; the first is to break into pieces, and the second means irregular. However, Mandelbrot gave another definition to fractals, describing them as geometric objects with characteristics of internal and invariable similarity structure. Besides, a fractal repeats its basic structure at different scales to increase it or reduce it, being appreciated in various forms of nature such as trees. Two characteristics are attributed to fractals:

- They are too irregular; therefore, they cannot be described with traditional geometric patterns.

- They are self-similar; in other words, they are small copies of the exact figure.

In [17], defines the fractal figure as "Irregular and complex set of structures formed through computational and mathematical algorithms, with basic figures such as points, straight lines and others of traditional mathematics," while [18] defines it as "very irregular shape, broken or fragmented at any scale, but with a distinctive feature or pattern." 
It is essential to differentiate between two concepts: "fractal set" and "natural fractal." The former is described as "a set of characteristics that can be defined through mathematics" while the latter is defined as a "natural object with regularity; for example clouds, trees or others" [17].

\section{B. Natural Patterns}

Nature has copious fractal patterns. [19] describes that there is no chaos in nature, and on the contrary, there are levels of order with their complex structures, which in nonlinear mathematical terms it is defined as self-ordering. These natural patterns can be found in different locations, such as snowflakes, honeycombs, ground cracks, peacock feathers, lightning, clouds, et. al.

In [20], the author explains that fractals must be understood in different ways, being one of them defined by Euclidean geometry. Said book [20] provides the reader with several examples such as galaxies, swirls, snowflakes, islands, branches, trees, lakes, cosmic dust, the coast of Great Britain, lunar craters, and others.

1) The fractal geometry of nature: It is complex to describe nature within the natural fractal geometry since its irregular and fragmented character could reach an endless level of complexity [21].

Euclidean Geometry discards the study of nature due to its amorphous essence. However, in addition to his fractal theory, Mandelbrot developed the Fractal Geometry of Nature, which permits the description of the irregular and fragmented patterns of nature and defines two relevant terms: "randomness" and "statistics" [20].

2) Human fractals: The concept refers to visual expressions created by people [19].

Human fractals are characterized by creativity, color combination, mystery, spirit, dynamism, and the mixture of these elements are said fractals [20]. These human creations can occur in diverse art fields such as painting, sculpture, music, film, digital art, and others. Among the best-known examples is Leonardo Da Vinci's work: "Drawing of a flood," where irregular and complex shapes of clouds and water are observed, as well as whirlpools of different sizes. Moreover, "The Big Wave" by Katsushika Hokusai [20] stands out as one of the first fractal paintings which focuses on elements such as the sea, waves, clouds, and treetops.

3) Koch snowflake: It has a complex aspect considered as natural fractal geometry [20]. It is usually compared to Great Britain's coasts due to its cascading shape, although the latter possesses a rudimentary pattern. The Koch Snowflake could be considered a fractal of simple nature; however, Euclidean Geometry defines it as complex.

4) Fractal and the algorithms of nature: Euclidean Geometry calculates approximations of nature's fractal geometry, helped by Computer-Aided Engineering, denominating this process as "Fractal Geometry" [22]. Fractal Geometry and Euclidean Geometry differ when working with circumferences and infinite repetitive processes, producing one of two situations:

- When increasing, the item can become a straight line or.

- When reducing, it will be lost at some point.

For Euclidean Geometry, the item can lose the original form, but for Fractal Geometry, it has the term of selfsimilarity, being noticed in reduction or enlargement operations. In order to get a diagram, it is necessary to use algorithms.

5) Biophilic design: Biophilia is defined as "the relationship between human beings and nature" [23]. The biophilic design incorporates patterns to the architecture (houses, buildings, interiors, et al.), which can be habitable by the human being as living space. This design presents more harmonic and non-traditionalist techniques and helps people in different aspects such as health through stress reduction, as shown by research conducted in [23]. Among other benefits, the article mentions the perception through cognitive function and development of creativity and intellect. A notable example of biophilic design is The Sphinx in Egypt. Nowadays, many biophilic designs can be found incorporating living organisms such as plants and animals or other replication designs from nature.

6) Fractals in textile industry: Computer-Aided Design (CAD) has helped in different areas to develop new production processes, being one of them the Textile Industry. With unique designs generated from creativity and productivity, CAD realizes automation, time reduction, customization, and product valuation. Thus, the use of fractals in the Textile Industry [24] has served to associate the idea of fractal as a product in the creation of garments, fabrication, printing, and others. Besides, with the implementation of algorithms, fractals generate products such as carpets, fabrics, leather, et. al.

The use of technology in the Textile Industry is not new. In [25], some trends were generated aided by software and simulators showing that technology can create complete collections and even individual and customized designs.

Observing the use of fractals in computer science is fascinating. However, it can be slightly complex because the fractal must be pre-designed, applying the image, processing techniques, algorithms, and others. For the design, it is possible to use digitalization or scanning techniques, color theory, deleting damaged areas with different software. It is also possible to select entirely or partially the work area and modify the size by reduction or enlargement.

Although there are programs that support the design, generate the image, program the algorithm, or simulators such as Corel Draw, they must be compatible. This is still a disadvantage since they operate independently, producing the risk of image loss which can occur when importing from one program to another, and this in the textile field could mean a significant loss. 


\section{3D Printing}

In [9], 3D printing is defined as "the sequential process to create objects in three dimensions from digitalized data, through the collection of material on a platform." On the other hand, [26] indicates that it is "a process where materials are combined to create objects in physical form from a digital design."

Domestic and industrial 3D printers have different uses depending on their application. Some processes are new and help to improve experimental areas, such as building housing, producing human tissues, and manufacturing spare parts in highly isolated places [27].

The process of layers resin salification was done through ultraviolet light. By the year 2000, 3D printing adds concepts such as additive manufacturing of casting patterns (Rapid Casting), production tools through injection molding (Rapid Tooling), and the gathering of production parts (Rapid Manufacturing). Due to these improvements, nowadays, 3D Printing is accessible and easier to use [26], emphasizing the digitalization of objects [28].

1) Printing techniques: According to the definitions reviewed, there are four techniques in 3D printing:

a) Additive: It is the union of various materials, techniques, equipment, et al.

b) Subtractive: Refers to the exclusion of material from the original design. These can be solid objects.

c) Transformation: Change of the material by other techniques and methods.

d) Hybrid: Combination of materials, processes, procedures, equipment, et al.

2) Rapid prototyping: It is a process to create new products, attempting to know the market's impact, and collecting answers for manufacturing. Rapid prototyping is an automated way to elaborate layers of different materials. It is commonly defined as "Layer Manufacturing, that allows obtaining prototypes with a wide range of materials, regardless the shape and geometric complexity, in a short time and without using other tools" [29].

\section{Digital Manufacturing}

In [27], it is defined as "the process of developing objects from digital files, using an equipment (machine) controlled by a computer."

Digital Manufacturing is a broad and technical process focused on the social aspect since many advantages can be obtained. Some of them customize products, reduce production costs, manufacture complex objects and nanometric precision provided by the software and programming languages that support it.

Nowadays, digital manufacturing is involved in different areas of knowledge directly or indirectly. For this purpose, it needs the complement of computer-controlled machines such as a Computer Numerical Control (CNC), which impacts different industries such as automotive, textile, or in some cases in people. It is open-source, promoting the exchange of information between development groups. However, it is possible that digital manufacturing becomes lucrative in the future since it will be shaped according to the needs of organizations and individuals [27].

\section{Methodology}

\section{A. Research Sample}

This research experiments with three proposed natural patterns defined by a hexagonal geometric design having the line variant and infill at $12 \%$. Two types of 3D printers have been utilized with two different flexible filaments described in the following (Table I).

\section{B. Equipment}

The equipment and tools used to conduct this research are described below.

1) $3 D$ printers: The $3 D$ printers employed for this study are Anet A8 and M3D Crane Quad (see Fig. 1 and 2). Their characteristics are described in Table II.

TABLE I. RESEARCH SAMPLES, Distribution OF THE 48 SAMPLES By FILAMENT, PATTERN, AND INFILL VARIANT

\begin{tabular}{|c|c|c|c|c|c|}
\hline \multirow{2}{*}{ Filament } & \multirow{2}{*}{$\begin{array}{l}\text { Natural } \\
\text { Pattern }\end{array}$} & \multirow{2}{*}{ Variant } & \multicolumn{2}{|c|}{ 3D Printer } & \multirow{2}{*}{ Total } \\
\hline & & & $\begin{array}{l}\text { A8 } \\
\text { Anet }\end{array}$ & $\begin{array}{l}\text { M3D Crane } \\
\text { Quad }\end{array}$ & \\
\hline \multirow{6}{*}{ TPU } & \multirow{2}{*}{ Snowflake } & Line & 2 & 2 & 4 \\
\hline & & Infill & 2 & 2 & 4 \\
\hline & \multirow{2}{*}{ Flower of life } & Line & 2 & 2 & 4 \\
\hline & & Infill & 2 & 2 & 4 \\
\hline & \multirow{2}{*}{ Honeycomb } & Line & 2 & 2 & 4 \\
\hline & & Infill & 2 & 2 & 4 \\
\hline \multirow{6}{*}{ TPE } & \multirow{2}{*}{ Snowflake } & Line & 2 & 2 & 4 \\
\hline & & Infill & 2 & 2 & 4 \\
\hline & \multirow{2}{*}{ Flower of life } & Line & 2 & 2 & 4 \\
\hline & & Infill & 2 & 2 & 4 \\
\hline & \multirow{2}{*}{ Honeycomb } & Line & 2 & 2 & 4 \\
\hline & & Infill & 2 & 2 & 4 \\
\hline
\end{tabular}

TABLE II. 3D PRINTERS FEATURES

\begin{tabular}{|l|l|l|}
\hline \multirow{2}{*}{ Feature } & \multicolumn{2}{|l|}{ 3D Printer } \\
\cline { 2 - 3 } & Anet A8 & M3D Crane Quad \\
\hline Nozzle Diameter & $0.4 \mathrm{~mm}$. & $0.35 \mathrm{~mm}$. \\
\hline Build Volume & $220 \times 220 \times 240 \mathrm{~mm}$. & $200 \times 200 \times 230 \mathrm{~mm}$. \\
\hline Printing Speed & $40-120 \mathrm{~mm} / \mathrm{s}$ & hasta $80 \mathrm{~mm} / \mathrm{s}$ \\
\hline Filament diameter & $1.75 \mathrm{~mm}$. & $1.75 \mathrm{~mm}$. \\
\hline
\end{tabular}




\section{2) Dynamometer (see Fig. 3)}

- Model: Thread Dynamometer model 848 from Instruments J. Bot S.A.

- Maximum Capacity: 10 kg.

- Elongation: $0.1 \%$ over $500 \mathrm{~mm}$.

- Upper clamp for wire

- Lower clamp for driving roller

3) Intelligent 3D Printing Pen (see Fig. 4)

- Brand: SUNLU 3rd generation.

- Model: SL-300.

- Temperature: ABS $180 \sim 210^{\circ} \mathrm{C}$ and PLA $160 \sim 180^{\circ} \mathrm{C}$.

- Filament diameter: $1.75 \mathrm{~mm}$.

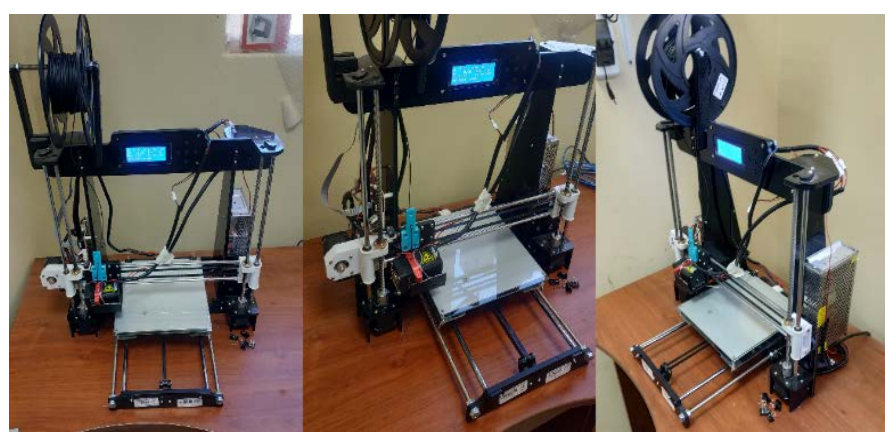

Fig. 1. Anet A8 3D Printer with $0.4 \mathrm{~mm}$. Nozzle Diameter and Modified to Print Flexible Filaments.

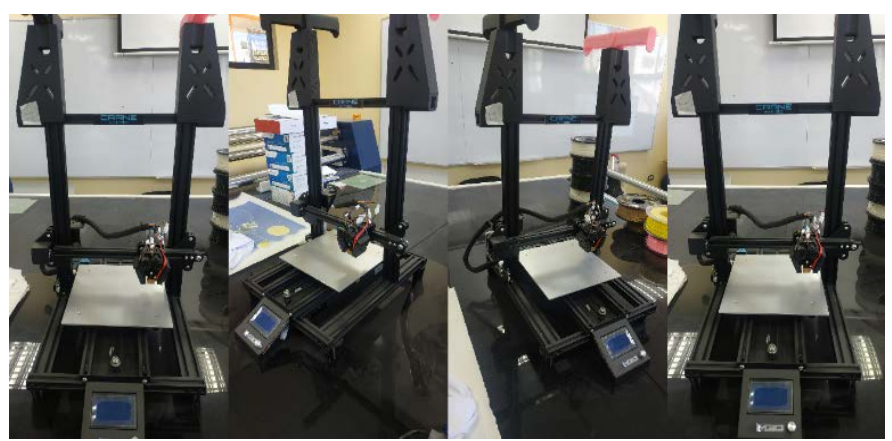

Fig. 2. M3D Crane Quad 3D Printer with $0.35 \mathrm{~mm}$. Nozzle Diameter and the Capacity to Combine Four Colors of Filaments.

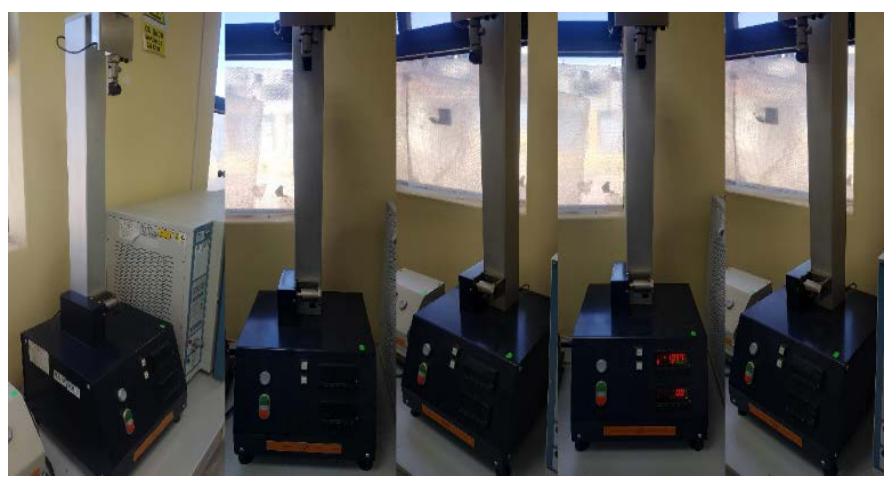

Fig. 3. Dynamometer Model 848 from J. Bot S.A. used in Tensile and Elongation Tests of the Printed Natural Patterns.

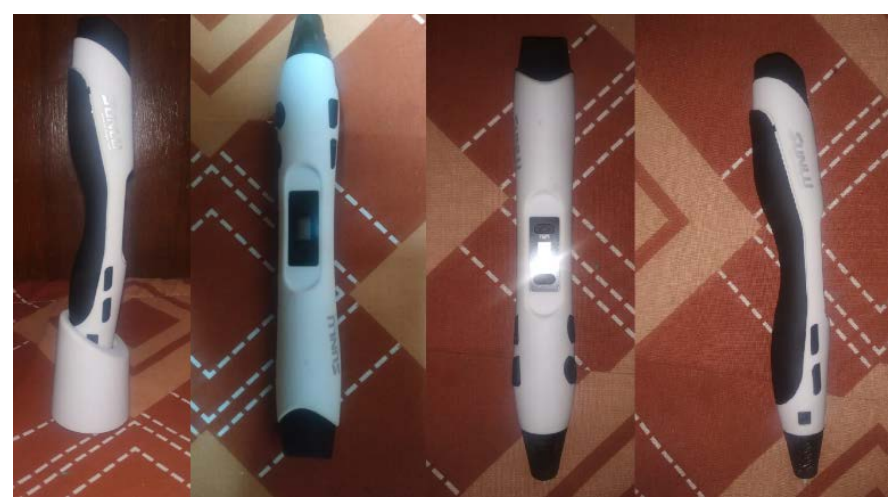

Fig. 4. Smart 3D Printer Pen SUNLU used to Join the 29 Pieces of the Garment Printed with the Snowflake Pattern.

\section{Software}

The software programs utilized for this research are described in the following.

1) Rhinoceros 6: 3D design and modeling software used to shape the patterns of the garment.

2) CLO 3D: Software for fashion design and simulation in 2D and 3D, which allowed the validation of dimensions and simulation of the garment with the selected pattern.

3) Voxelizer 2.1: A 3D printing software that permitted the generation of the GCODE file.

4) Plug-in: The author downloaded three plug-ins and used them in the Rhinoceros design and simulation. These are Trace, SymmetryArrow, and Trim Arrow.

\section{Procedures Research}

1) Natural Patterns: The design of the main pattern takes natural forms as a reference. Such models are defined by hexagonal geometry, permitting an easy union through the network.

While in [4], the author was inspired by the mesostructured cellular pattern by Andreas Bastian; in [9], the main design was the Brain coral adjusted to hexagonal geometry (see Fig. 5).

This research used three natural hexagonal patterns: "Snowflake," "Honeycomb," and "Flower of Life" (see Fig. 6). The dimensions of the natural patterns are described in the Table III. The mentioned patterns have been modified to continue with their digitalization. Lastly, corrections were applied to the line variant and infill density (see Fig. 7, 8 and 9).

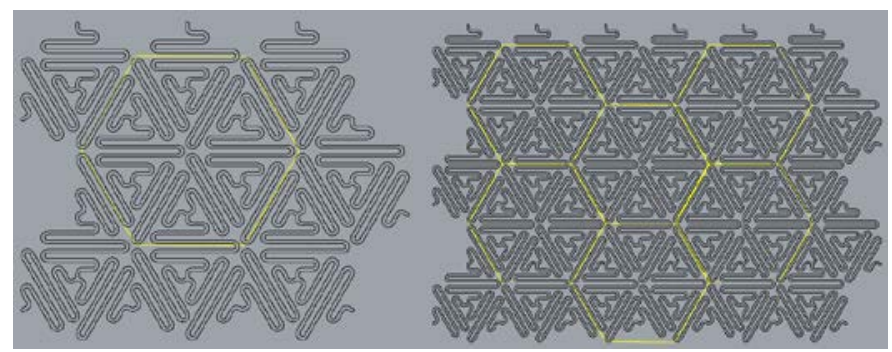

Fig. 5. Mesostructured Cellular Pattern with Hexagonal Geometry by Andreas Bastian, Showing the Union of the Patterns. 


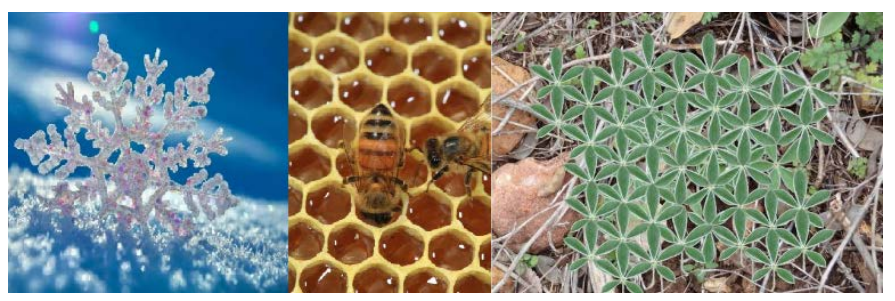

Fig. 6. Natural Patterns "Snowflake," "Honeycomb," and "Flower of Life" used for the Traction and Elongation Tests and Subsequent Garment Elaboration.

TABLE III. MEASUREMENTS OF PROPOSED NATURAL PATtERNS

\begin{tabular}{|l|l|l|}
\hline \multirow{2}{*}{ Natural Pattern } & \multicolumn{2}{|l|}{ Variant } \\
\cline { 2 - 3 } & Line & Infill \\
\hline Snowflake & $13.2 \times 10.8 \times 0.15 \mathrm{~cm}$. & $13 \times 9.4 \times 0.15 \mathrm{~cm}$. \\
\hline Honeycomb & $10.9 \times 7.5 \times 0.15 \mathrm{~cm}$. & $10.9 \times 8.9 \times 0.15 \mathrm{~cm}$. \\
\hline Flower of life & $11.7 \times 10.7 \times 0.15 \mathrm{~cm}$. & $11.3 \times 10.3 \times 0.15 \mathrm{~cm}$. \\
\hline
\end{tabular}
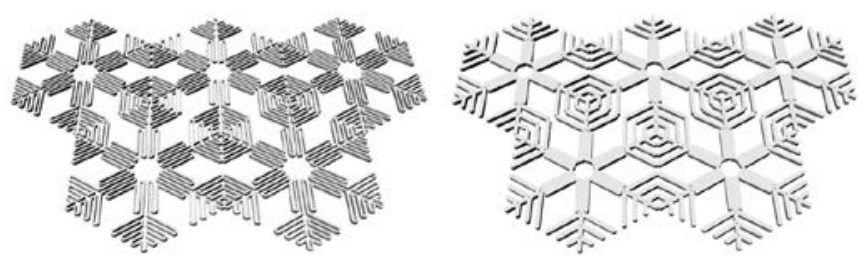

Fig. 7. Snowflake Pattern Line Variant and Infill Density, Digitalized through Rhinoceros 6 Software.
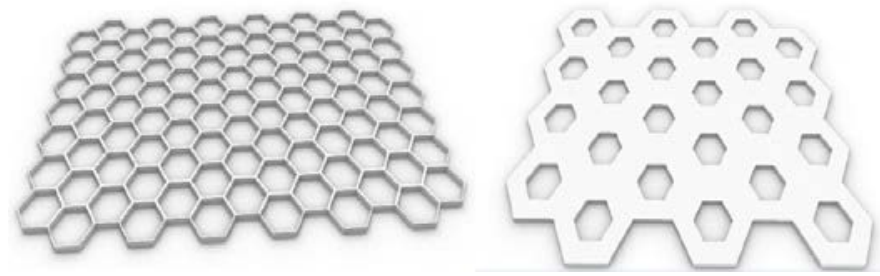

Fig. 8. Snowflake Pattern Line Variant and Infill Density, Digitalized through Rhinoceros 6 Software.
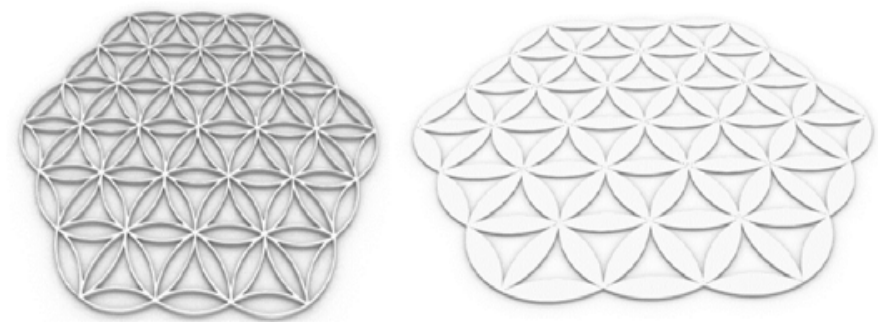

Fig. 9. Flower of Life Pattern Line Variant and Infill Density, Digitalized through Rhinoceros 6 Software.

2) Printing process: For this research, the two $3 D$ printer filaments used were TPU and TPE. The combination of filaments, printers, line variant, and infill density resulted in forty-eight (48) samples printed. While the first sample was named "P1", the second unit was called "P2". The technical specifications of the printing are described in the Table IV.
TABLE IV. TECHNICAL SPECIFICATIONS OF THE 3D PRINTER

PARAMETERS CONFIGURATION FOR THE CREATION OF THE PATTERNS

\begin{tabular}{|l|l|l|}
\hline \multirow{2}{*}{ Parameter } & \multicolumn{2}{|l|}{ 3D Printer } \\
\cline { 2 - 3 } & Anet A8 & M3D Crane Quad \\
\hline Extruder temperature & $240^{\circ} \mathrm{C}$ & $240^{\circ} \mathrm{C}$ \\
\hline Hotbed temperature & $70^{\circ} \mathrm{C}$ & $70^{\circ} \mathrm{C}$ \\
\hline Quality Print & $60 \%$ & $60 \%$ \\
\hline Infill & $12 \%$ & $12 \%$ \\
\hline Raft & No & No \\
\hline Retraction & No & No \\
\hline Support & No & No \\
\hline Resolution & $0.22 \mathrm{~mm}$. & $0.22 \mathrm{~mm}$. \\
\hline
\end{tabular}

3) Tests: For the purpose of this research, two tests were carried out on the samples: The elongation and tensile strength test. The elongation test consists of applying a variable force to each exemplar in order to obtain the percentage of its elastic limit before reaching its fracture point. The tensile test applies a variable vertical power to each design to determine how it will behave under particular pressure (see Fig. 10, 11, 12, 13, 14, and 15).

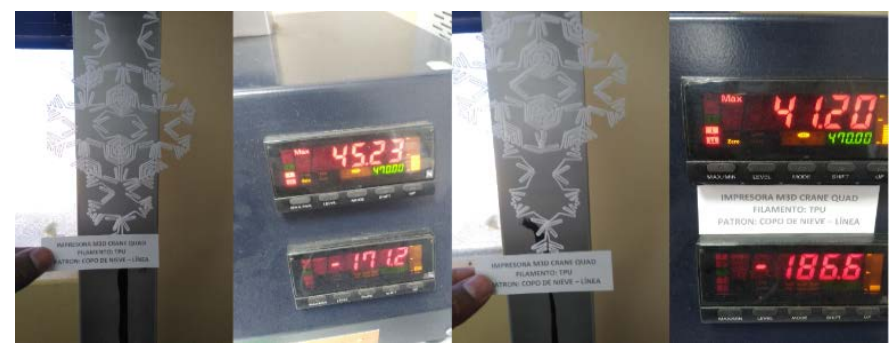

Fig. 10. Tensile and Elongation Tests of Snowflake Pattern with Line Variant, Printed with TPU and TPE Flexible Filaments.

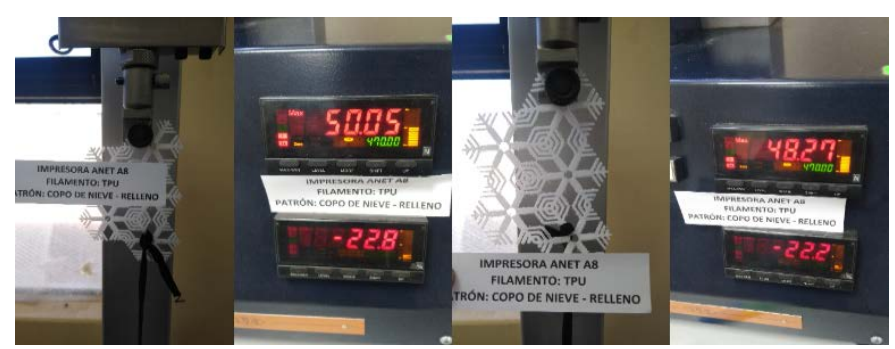

Fig. 11. Tensile and Elongation Tests of Snowflake Pattern with Infill, Printed with TPU and TPE Flexible Filaments.

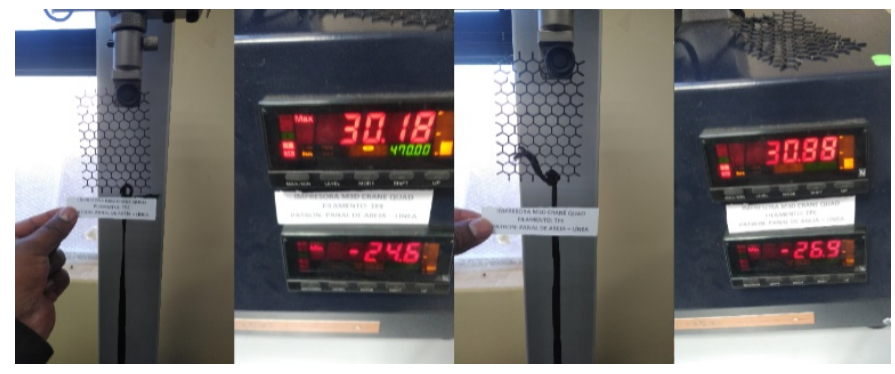

Fig. 12. Tensile and Elongation Tests of Honeycomb Pattern with Line Variant, Printed with TPU and TPE Flexible Filaments. 


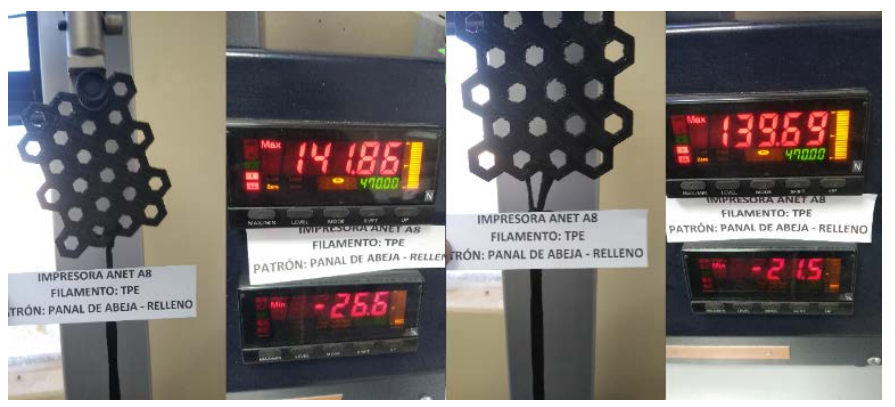

Fig. 13. Tensile and Elongation Tests of Honeycomb Pattern with Infill, Printed with TPU and TPE Flexible Filaments.

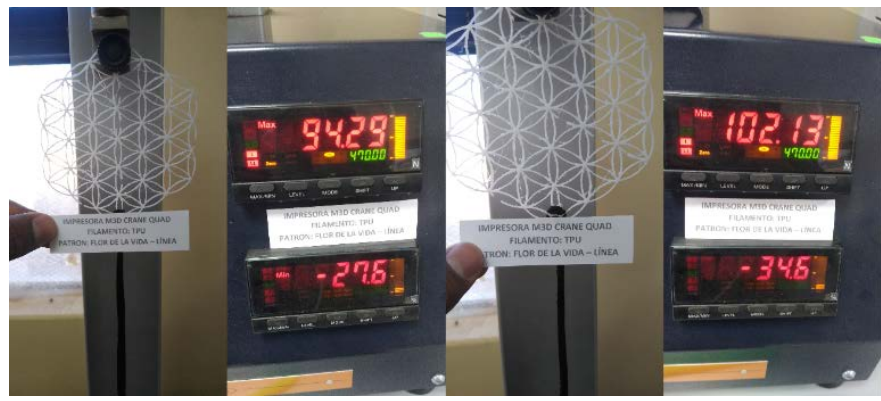

Fig. 14. Tensile and Elongation Tests of Flower of Life Pattern with Line, Printed with TPU and TPE Flexible Filaments.

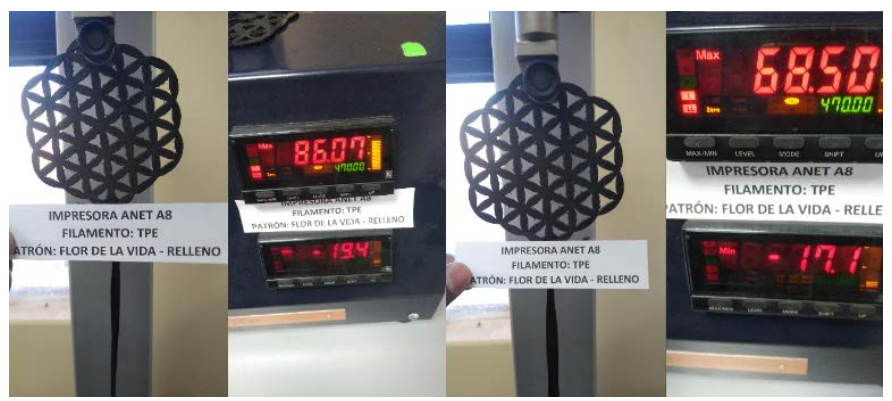

Fig. 15. Tensile and Elongations Tests of Flower of Life with Infill, Printed with TPU and TPE Flexible Filaments.

4) Digitalization of the garment: The performed tests showed that the most optimal model to use for the research was the snowflake pattern.

Subsequently, using Rhinoceros 6, the selected pattern was placed in twenty-five columns with thirteen and fourteen repetitions. The latter created a rectangular area of $95.65 \mathrm{~cm} . \mathrm{x}$ $61.23 \mathrm{~cm} . \times 0.15 \mathrm{~cm}$., ideal to proceed with the garment's design (see Fig. 16).

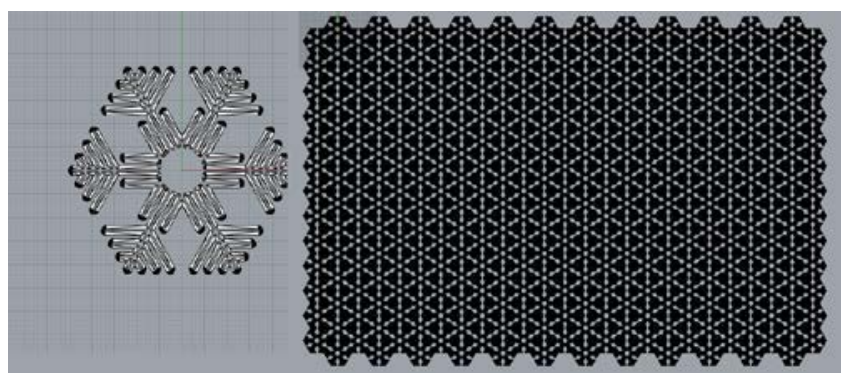

Fig. 16. Snowflake Pattern and Column Sorting, Simulating Fabric Cutting and Subsequent Division into 29 Pieces.
The rectangular area formed by the pattern was imported in image format (PNG) to the CLO 3D Software. Subsequently, the garment's necessary sections were delimited in the mentioned software, as shown in Fig. 17. Size "M" was taken as a reference since it is common among clothes of women (see Fig. 17).

With the model entirely designed, the authors returned to Rhinoceros and deleted the patterns that were not needed (see Fig. 18). The author deleted column 25 to obtain regular patterns to print, as shown in Fig. 18.

The current workspace was exported again in PNG to CLOE 3D to perform the garment simulation with TPU and TPE filaments (see Fig. 19).

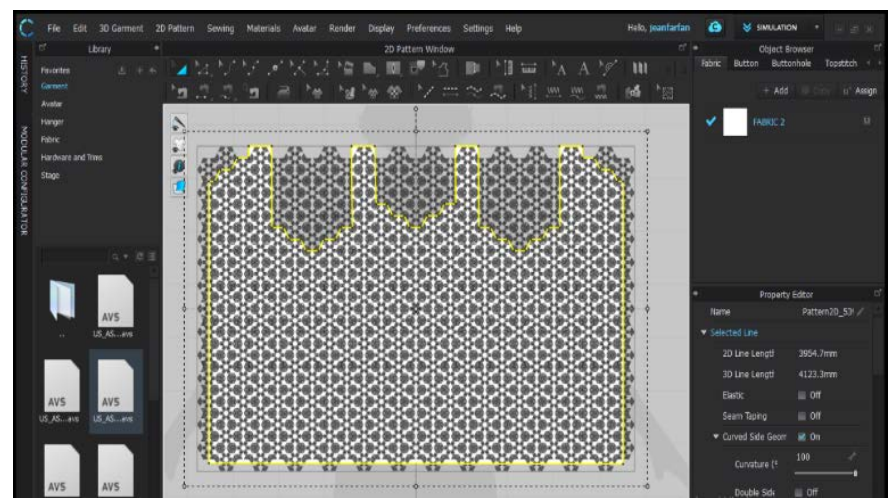

Fig. 17. Design of the Garment on the Rectangular Working Area in CLO 3D Software in Order to Delete Areas of Pattern Located Outside the Garment Area in the Yellow Region.

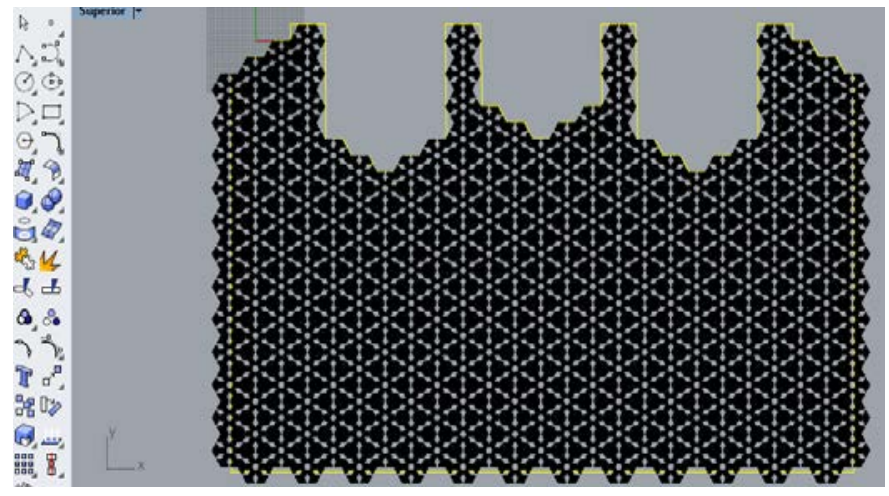

Fig. 18. Deleting Non-Essentials Areas of the Garment in Rhinoceros 6 Software to Simulate the Real Garment.

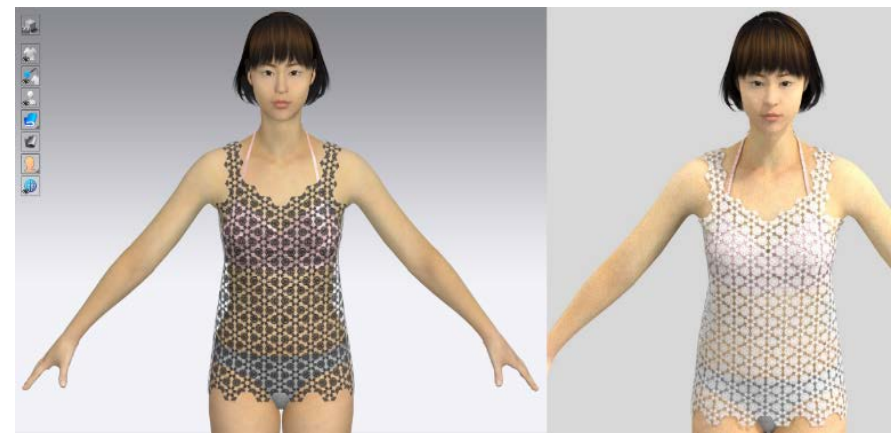

Fig. 19. Garment Simulation with TPE and TPU Flexible Filaments in CLO 3D Software for a Woman of Size M. 
Due to the printers' size of printing area used for this study, the whole pattern was divided into 29 pieces of $20 \mathrm{~cm} \times 20 \mathrm{~cm}$. (see Fig. 20). Such parts were named with a number from left to right and from the bottom to top. The fragments from 1 to 18 are equal, simplifying exporting to GCODE format (see Fig. 21).

Fragments from 1 to 18 were joined initially, continuing with sections from 19 to 29 to obtain a single item. Lastly, each edge of this single piece was joined together (see Fig. 22 and 24), forming the mentioned garment (see Fig. 26 and 27). The printed pieces' union was achieved using the 3D pen applying its corresponding filament (TPE and TPU) inside the garment at $185 \mathrm{C}^{\circ}$ (see Fig. 23 and 25).

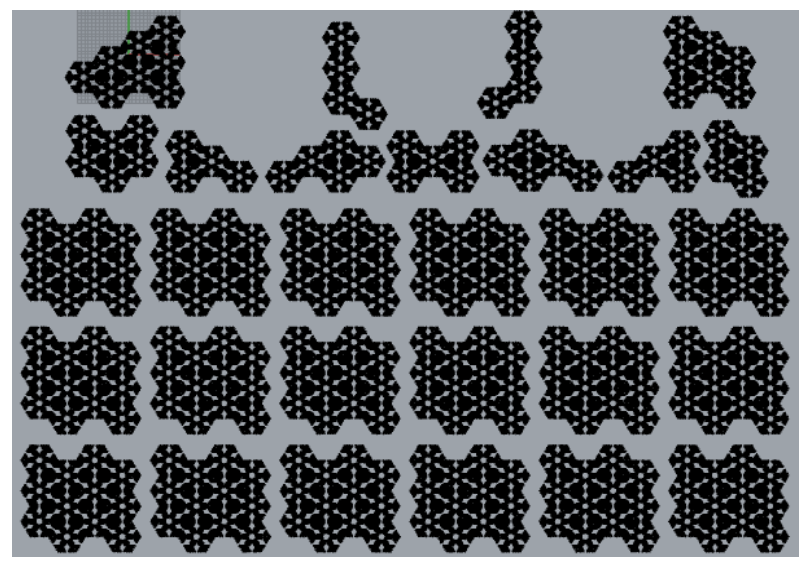

Fig. 20. Preparation of 29 Pieces of Garment for 3D Printing Exported in STL File Format.

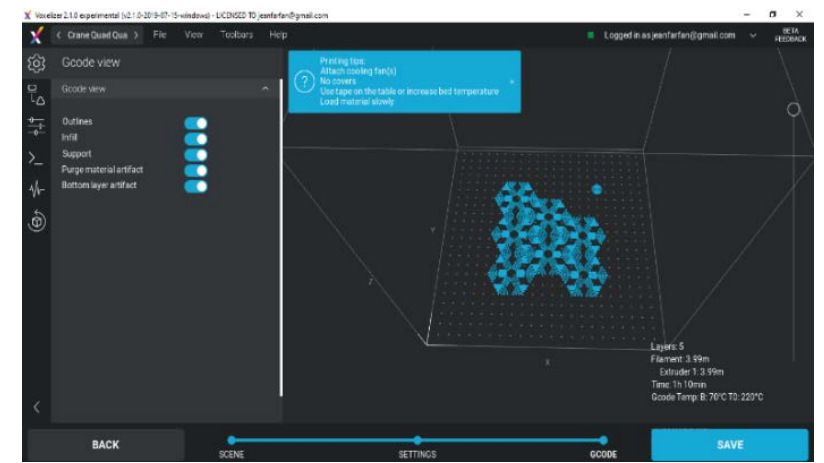

Fig. 21. Generation of the GCODE File through Voxelizer 2.0 Software for 3D Printing.

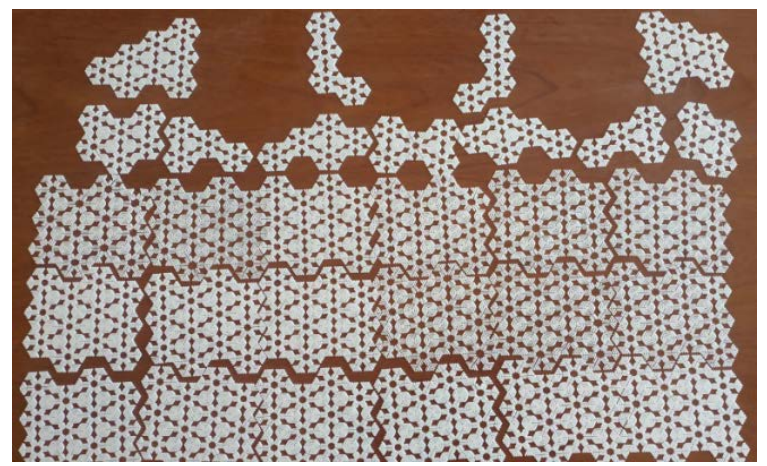

Fig. 22. Printed Garment's Parts with TPU Flexible Filament, Ordered from 1 to 29, from Left to Right, and from Bottom to Top.

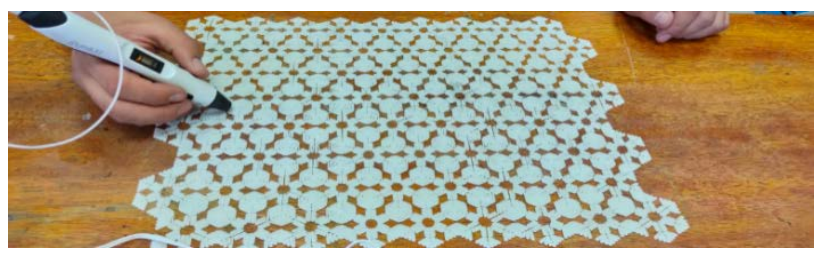

Fig. 23. Union of garment parts with TPU Filament using the 3D Smart-Pen.

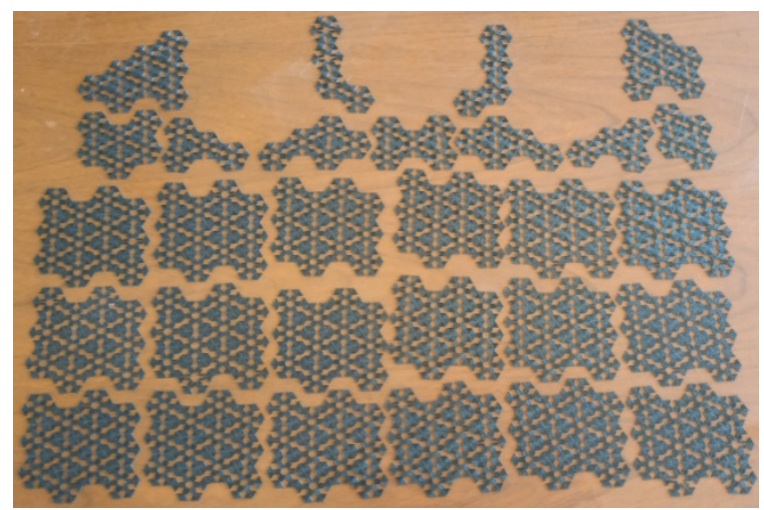

Fig. 24. Printer Garment Pieces with TPE Flexible Filament, Ordered from 1 to 29, from Left to Right, and from Bottom to Top.

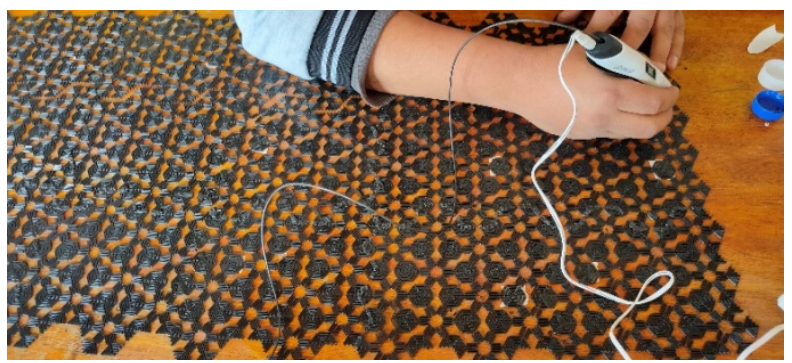

Fig. 25. Union of Garment Parts with TPE Filament using the 3D Smart-Pen.

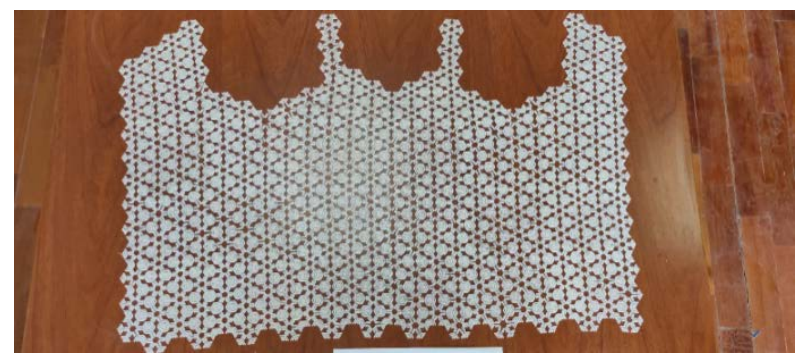

Fig. 26. The Garment used in the Research Printed with TPU Flexible Filament after Completing the Process of Joining Parts with the 3D SmartPen.

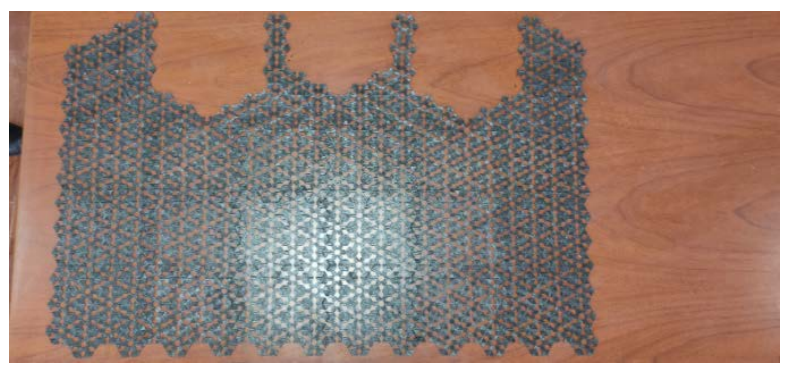

Fig. 27. The Garment used in the research Printed with TPE Flexible Filament after Completing the Process of Joining Parts with the 3D SmartPen. 
5) Presentation of the garment: Volunteers of S, M, L, and XL size, were asked to model the official presentation's garment. The volunteers wore the printed item of clothing, combining it with a skirt, a jacket, and jeans, as shown in Fig. 28, 29, 30 and 31.

Tables V, VI, and VII shows garments time and weight in both 3D printers and flexible filaments.

TABLE V. Statistical Data of Printed Pieces With TPU FleXible FILAMENT

\begin{tabular}{|c|c|c|c|c|c|}
\hline \multirow{3}{*}{ Piece } & \multirow{3}{*}{$\begin{array}{l}\text { Dimensions } \\
\text { (in cm.) }\end{array}$} & \multicolumn{4}{|c|}{ 3D Printer } \\
\hline & & \multicolumn{2}{|c|}{ A8 Anet } & \multicolumn{2}{|c|}{ M3D Crane Quad } \\
\hline & & $\begin{array}{l}\text { Time } \\
\text { (h:m) }\end{array}$ & $\begin{array}{l}\text { Weight } \\
\text { (g.) }\end{array}$ & $\begin{array}{l}\text { Time } \\
\text { (h:m) }\end{array}$ & $\begin{array}{l}\text { Weight } \\
\text { (g.) }\end{array}$ \\
\hline 1 & $16.37 \times 15.35$ & 01:42 & 15.74 & 01:49 & 10.94 \\
\hline 2 & $16.37 \times 15.35$ & 01:45 & 16.17 & 01:51 & 11.44 \\
\hline 3 & $16.37 \times 15.35$ & 01:44 & 16.06 & 01:48 & 9.45 \\
\hline 4 & $16.37 \times 15.35$ & 01:42 & 15.91 & 01:52 & 12.96 \\
\hline 5 & $16.37 \times 15.35$ & 01:43 & 15.99 & 01:51 & 11.47 \\
\hline 6 & $16.37 \times 15.35$ & 01:44 & 16.20 & 01:49 & 10.63 \\
\hline 7 & $16.37 \times 15.35$ & 01:43 & 15.83 & 01:50 & 12.40 \\
\hline 8 & $16.37 \times 15.35$ & 01:44 & 16.01 & 01:49 & 11.04 \\
\hline 9 & $16.37 \times 15.35$ & 01:43 & 15.91 & 01:49 & 11.45 \\
\hline 10 & $16.37 \times 15.35$ & 01:43 & 16.00 & 01:49 & 11.43 \\
\hline 11 & $16.37 \times 15.35$ & 01:44 & 16.34 & 01:48 & 10.56 \\
\hline 12 & $16.37 \times 15.35$ & 01:45 & 16.46 & 01:47 & 8.95 \\
\hline 13 & $16.37 \times 15.35$ & 01:44 & 16.35 & 01:47 & 9.78 \\
\hline 14 & $16.37 \times 15.35$ & 01:48 & 16.22 & 01:50 & 12.75 \\
\hline 15 & $16.37 \times 15.35$ & 01:44 & 16.46 & 01:50 & 12.06 \\
\hline 16 & $16.37 \times 15.35$ & 01:46 & 16.12 & 01:51 & 12.52 \\
\hline 17 & $16.37 \times 15.35$ & 01:47 & 16.00 & 01:53 & 13.89 \\
\hline 18 & $16.37 \times 15.35$ & 01:47 & 16.31 & 01:51 & 11.29 \\
\hline 19 & $12.60 \times 10.98$ & $00: 50$ & 7.82 & $00: 58$ & 5.62 \\
\hline 20 & $12.60 \times 8.79$ & $00: 32$ & 5.04 & 00:39 & 4.00 \\
\hline 21 & $16.38 \times 8.79$ & $00: 41$ & 5.78 & $00: 50$ & 4.76 \\
\hline 22 & $12.60 \times 8.79$ & 00:41 & 6.49 & $00: 49$ & 4.81 \\
\hline 23 & $16.38 \times 8.79$ & 00:41 & 6.36 & $00: 50$ & 4.80 \\
\hline 24 & $12.60 \times 8.79$ & 00:32 & 5.53 & $00: 39$ & 3.34 \\
\hline 25 & $8.24 \times 10.92$ & $00: 32$ & 4.58 & 00:39 & 4.14 \\
\hline 26 & $16.37 \times 13.16$ & 01:07 & 9.30 & 01:21 & 7.87 \\
\hline 27 & $8.82 \times 15.34$ & $00: 32$ & 4.77 & 00:39 & 3.92 \\
\hline 28 & $8.82 \times 15.34$ & $00: 32$ & 5.09 & 00:39 & 3.52 \\
\hline 29 & $12.60 \times 13.16$ & 00:58 & 8.62 & $01: 10$ & 6.65 \\
\hline
\end{tabular}

TABLE VI. Statistical Data of Printed Pieces with TPE FleXible FILAMENT

\begin{tabular}{|c|c|c|c|c|c|}
\hline \multirow{3}{*}{ Piece } & \multirow{3}{*}{$\begin{array}{l}\text { Dimensions } \\
\text { (in } \mathrm{cm} \text {.) }\end{array}$} & \multicolumn{4}{|c|}{ 3D Printer } \\
\hline & & \multicolumn{2}{|c|}{ A8 Anet } & \multicolumn{2}{|c|}{ M3D Crane Quad } \\
\hline & & $\begin{array}{l}\text { Time } \\
\text { (h:m) }\end{array}$ & $\begin{array}{l}\text { Weight } \\
\text { (g.) }\end{array}$ & $\begin{array}{l}\text { Time } \\
\text { (h:m) }\end{array}$ & $\begin{array}{l}\text { Weight } \\
\text { (g.) }\end{array}$ \\
\hline 1 & 16.37 x 15.35 & 01:41 & 16.56 & 02:02 & 14.10 \\
\hline 2 & 16.37 x 15.35 & 01:42 & 16.87 & 02:03 & 14.24 \\
\hline 3 & 16.37 x 15.35 & 01:40 & 16.42 & 02:02 & 14.19 \\
\hline 4 & 16.37 x 15.35 & 01:39 & 14.01 & 02:01 & 14.00 \\
\hline 5 & 16.37 x 15.35 & 01:40 & 16.45 & 02:03 & 14.28 \\
\hline 6 & 16.37 x 15.35 & 01:39 & 16.20 & 02:02 & 14.25 \\
\hline 7 & 16.37 x 15.35 & 01:41 & 16.56 & $01: 59$ & 11.21 \\
\hline 8 & 16.37 x 15.35 & 01:41 & 16.59 & 02:01 & 13.98 \\
\hline 9 & 16.37 x 15.35 & 01:40 & 16.34 & 02:03 & 14.34 \\
\hline 10 & 16.37 x 15.35 & 01:42 & 16.73 & 02:00 & 13.26 \\
\hline 11 & 16.37 x 15.35 & 01:43 & 16.62 & 02:02 & 14.15 \\
\hline 12 & 16.37 x 15.35 & 01:40 & 16.31 & 02:02 & 14.14 \\
\hline 13 & 16.37 x 15.35 & 01:43 & 16.72 & 02:04 & 14.64 \\
\hline 14 & $16.37 \times 15.35$ & 01:41 & 16.40 & 02:02 & 14.26 \\
\hline 15 & 16.37 x 15.35 & 01:41 & 16.41 & 02:02 & 14.16 \\
\hline 16 & 16.37 x 15.35 & 01:41 & 16.41 & 02:02 & 14.21 \\
\hline 17 & 16.37 x 15.35 & 01:39 & 16.23 & 02:02 & 14.26 \\
\hline 18 & 16.37 x 15.35 & 01:40 & 16.27 & 02:03 & 14.57 \\
\hline 19 & $12.60 \times 10.98$ & $00: 50$ & 8.47 & 01:01 & 6.71 \\
\hline 20 & $12.60 \times 8.79$ & $00: 32$ & 5.57 & $00: 39$ & 4.75 \\
\hline 21 & $16.38 \times 8.79$ & $00: 41$ & 7.07 & $00: 50$ & 5.96 \\
\hline 22 & $12.60 \times 8.79$ & 00:41 & 7.12 & $00: 49$ & 5.94 \\
\hline 23 & $16.38 \times 8.79$ & $00: 41$ & 7.01 & $00: 50$ & 5.93 \\
\hline 24 & $12.60 \times 8.79$ & $00: 32$ & 5.60 & $00: 39$ & 4.76 \\
\hline 25 & $8.24 \times 10.92$ & $00: 32$ & 5.63 & $00: 39$ & 4.75 \\
\hline 26 & $16.37 \times 13.16$ & 01:08 & 11.10 & $01: 22$ & 9.48 \\
\hline 27 & $8.82 \times 15.34$ & $00: 32$ & 5.61 & 00:39 & 4.76 \\
\hline 28 & $8.82 \times 15.34$ & $00: 32$ & 5.60 & 00:39 & 4.76 \\
\hline 29 & $12.60 \times 13.16$ & $00: 58$ & 9.80 & 01:11 & 8.29 \\
\hline
\end{tabular}

TABLE VII. STATISTICAL DATA OF GARMENTS

\begin{tabular}{|l|l|l|l|l|}
\hline \multirow{2}{*}{ Filament } & \multicolumn{3}{|l|}{ 3D Printer } & \multicolumn{2}{l|}{ M3D Crane Quad } \\
\cline { 2 - 5 } & A8 Anet & $\begin{array}{l}\text { Weight } \\
\text { (g.) }\end{array}$ & $\begin{array}{l}\text { Time } \\
\text { (h:m) }\end{array}$ & $\begin{array}{l}\text { Weight } \\
(\boldsymbol{g} .)\end{array}$ \\
\cline { 2 - 5 } & $\begin{array}{l}\text { Time } \\
\text { (h:m) }\end{array}$ & 359.46 & $42: 07$ & 258.44 \\
\hline TPU & $38: 56$ & 372.68 & $45: 53$ & 318.33 \\
\hline TPE & $37: 52$ & \multicolumn{3}{|l}{} \\
\hline
\end{tabular}




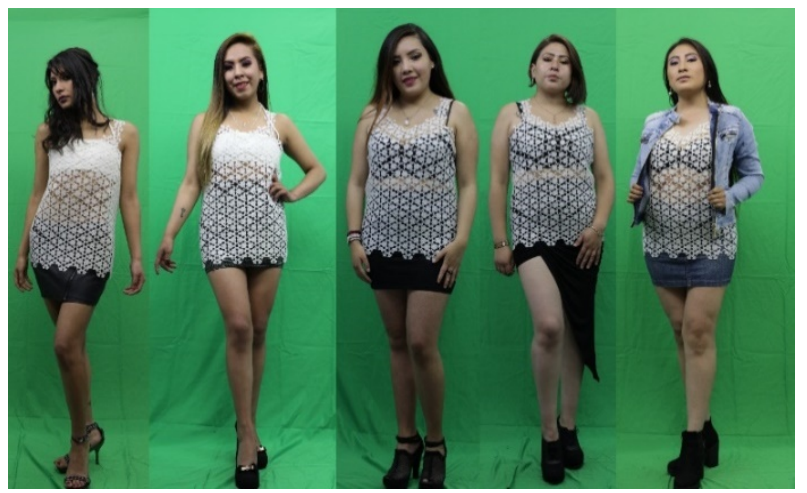

Fig. 28. Volunteers Wearing the Garment Printed with TPU Filament in the Anet A8 Printer.

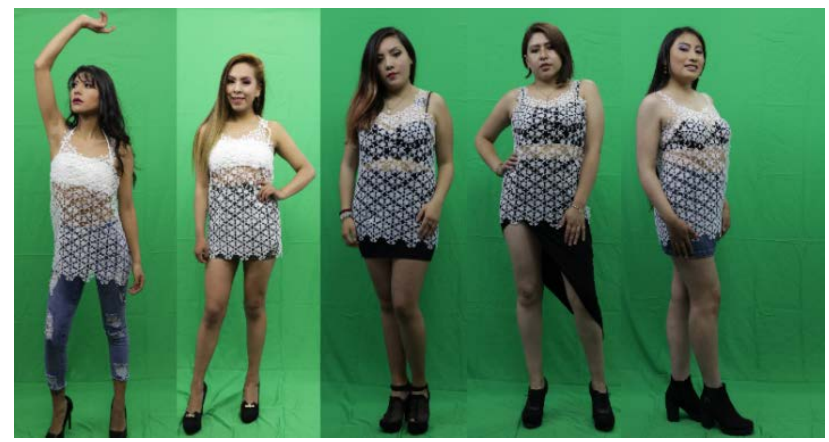

Fig. 29. Volunteers Wearing the Garment Printed with TPU Filament in the M3D Crane Quad Printer.

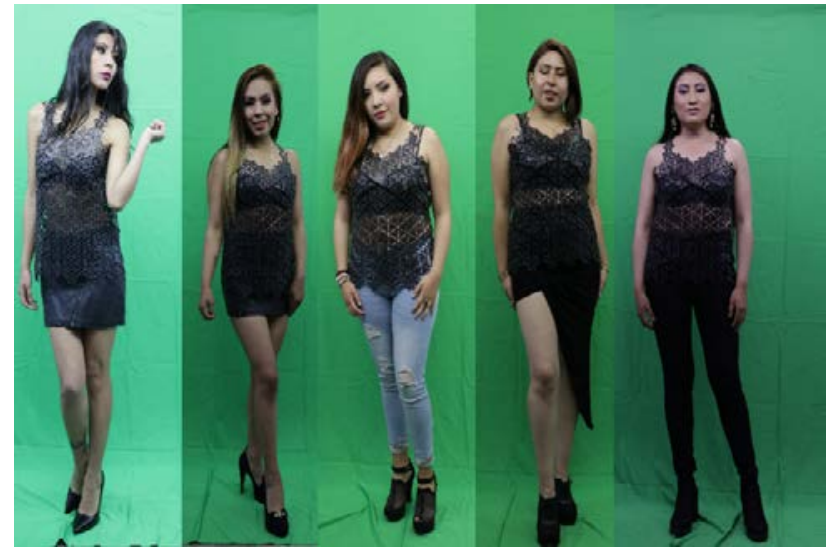

Fig. 30. Volunteers Wearing the Garment Printed with TPE Filament in the Anet A8 Printer.

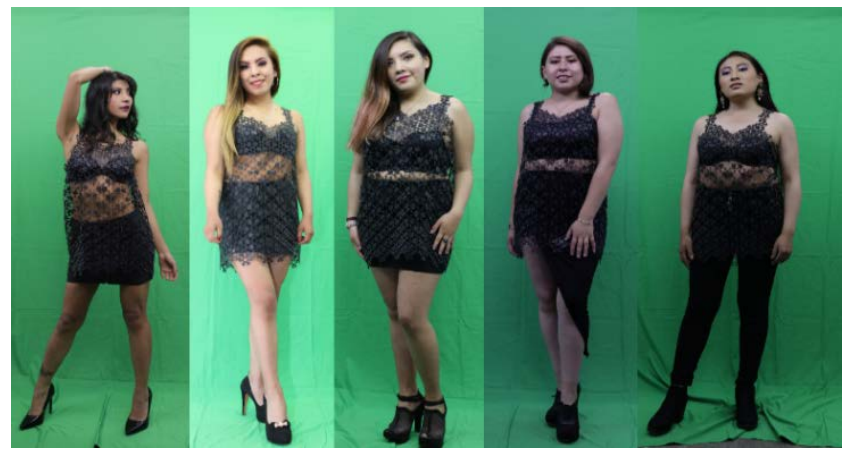

Fig. 31. Volunteers Wearing the Garment Printed with TPE Filament in the M3D Crane Quad Printer.

\section{RESULTS}

\section{A. Elongation Test}

In Table VIII, shows the results obtained from the garment design's primary test.

In Table IX, the Elongation test, the authors executed an analysis of variance (ANOVA), which was significant and applicable for filament and pattern factors (see Fig. 32).

TABLE VIII. RESULTS OF ELONGATION TEST

\begin{tabular}{|l|l|l|l|l|l|}
\hline \multirow{4}{*}{ Filament } & \multirow{3}{*}{ Natural Pattern } & \multicolumn{3}{|l|}{ 3D Printer } \\
\cline { 3 - 6 } & & \multicolumn{2}{|l}{$\begin{array}{l}\text { A3D Crane } \\
\text { Quad }\end{array}$} \\
\cline { 3 - 6 } & P1 & P2 & P1 & P2 \\
\hline \multirow{5}{*}{ TPU } & Snowflake Line & 166.90 & 171.20 & 197.00 & 186.60 \\
\cline { 2 - 6 } & Snowflake Infill & 22.80 & 18.50 & 22.20 & 16.50 \\
\cline { 2 - 6 } & Flower of Life Line & 31.50 & 36.30 & 33.00 & 37.00 \\
\cline { 2 - 6 } & Flower of Life Infill & 45.00 & 21.80 & 38.20 & 20.70 \\
\cline { 2 - 6 } & Honeycomb Line & 20.90 & 27.60 & 16.90 & 34.60 \\
\cline { 2 - 6 } & Honeycomb Infill & 21.70 & 14.00 & 19.50 & 13.20 \\
\hline \multirow{5}{*}{ TPE } & Snowflake Line & 147.30 & 160.80 & 117.40 & 161.60 \\
\cline { 2 - 6 } & Snowflake Infill & 15.30 & 18.40 & 17.90 & 15.20 \\
\cline { 2 - 6 } & Flower of Life Line & 28.90 & 24.60 & 27.80 & 26.90 \\
\cline { 2 - 6 } & Flower of Life Infill & 26.60 & 23.00 & 21.50 & 23.60 \\
\cline { 2 - 6 } & Honeycomb Line & 12.90 & 24.70 & 22.10 & 27.40 \\
\cline { 2 - 6 } & Honeycomb Infill & 19.40 & 9.90 & 17.10 & 13.30 \\
\hline
\end{tabular}

TABLE IX. RESUlTS OF ANOVA REgARDING ELONGATION TEST

\begin{tabular}{|l|l|l|l|l|l|}
\hline Source & df & $\begin{array}{l}\text { Sum of } \\
\text { Squares }\end{array}$ & $\begin{array}{l}\text { Mean } \\
\text { Square }\end{array}$ & F & Sig. \\
\hline Filament (A) & 1 & 1102.083 & 1102.083 & 14.254 & 0.001 \\
\hline Pattern (B) & 5 & 132604.819 & 26520.964 & 343.019 & 0.000 \\
\hline A x B & 5 & 1444.249 & 288.850 & 3.736 & 0.008 \\
\hline Error & 36 & 2783.385 & 77.3160 & & \\
\hline Total & $\mathbf{4 7}$ & $\mathbf{1 3 7 9 3 4 . 5 3 7}$ & & & \\
\hline
\end{tabular}

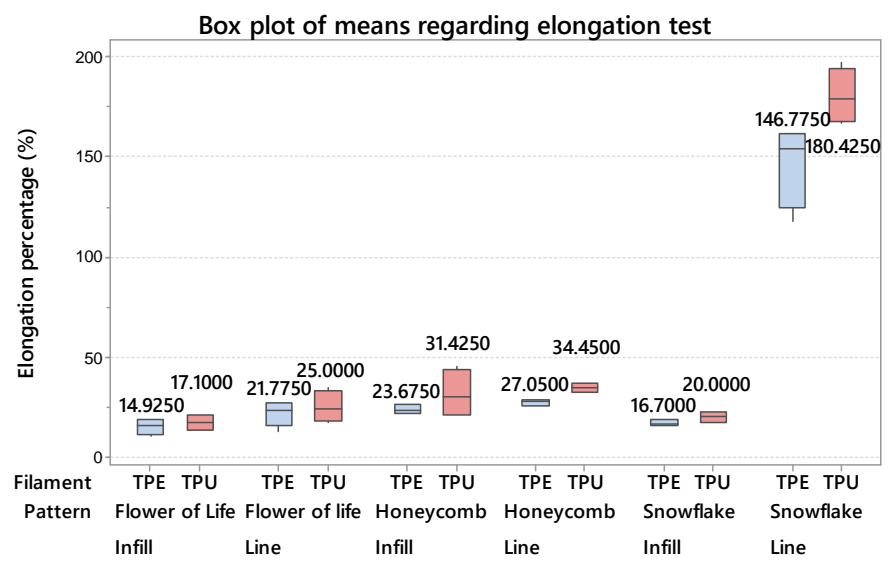

Fig. 32. Box Plot of Elongation Test Means Regarding Pattern and Flexible Filament. 
Flexible filament factor (A). - The F-value $=14.254$ leaves on the right a p-value of 0.001 , in other words, a significant value. It can be concluded that the design is significant and the inclusion is successful. Thus, the elongation test depends on the filament factor when making the garment.

Pattern factor (B). - The F-value $=343.019$ leaves on the right a p-value of 0.000 , which is interpreted as a significant value. The result suggests that some pattern significantly influences the elaboration of the garment. In other words, there are significant differences between designs.

A $x$ B. - This row captures the influence of all filament and pattern interactions. The value of $\mathrm{F}=3.736$ leaves on the right a $\mathrm{p}$-value of 0.008 , lower than the $5 \%$ significance level. There is sufficient evidence that there is an interaction between filament and pattern, or in other words, the studied factors are dependent on each other.

Error. - This row refers to the variance of the dependent variable not explained by the model.

Total. - This row shows the variance observed in the dependent variable caused by all the factors.

However, the ANOVA does not determine which treatment has the most significant average increase. A T-test was performed between flexible filament (A) and pattern(B) to find the mentioned value.

Flexible Filament (A). Table XII show the results of the Ttest $(\mathrm{P} \geq 0.457)$. There is no statistical difference between the TPU and TPE filament during the elongation test (see Table X and Fig. 33).

Pattern (B). Table XI and Fig. 34 show the results of Duncan's new multiple range test $(\mathrm{P} \leq 0.05)$. It shows exemplars' performance for the Elongation test where the Snowflake pattern (163.6\%) has a higher average score, indicating that it is statistically different from other designs.

TABLE X. INDEPENDENT SAMPLES OF ELONGATION REGARDING FLEXIBLE FILAMENT

\begin{tabular}{|l|l|l|l|l|}
\hline Filament & N & Mean & $\begin{array}{l}\text { Std. } \\
\text { Deviation }\end{array}$ & Std. Error Mean \\
\hline TPU & 24 & 51,4000 & 59,73579 & 12,19352 \\
\hline TPE & 24 & 41,8167 & 48,79419 & 9,96007 \\
\hline
\end{tabular}

TABLE XII. RESUlts OF T-TEST FOR THE ELONGATION REGARDING FLEXIBLE FILAMENT

\begin{tabular}{|c|c|c|c|c|c|c|c|c|c|}
\hline & \multicolumn{2}{|c|}{$\begin{array}{l}\text { Levene's Test for } \\
\text { Equality of Variances }\end{array}$} & \multicolumn{7}{|c|}{ T-test for Equality of Means } \\
\hline & \multirow{2}{*}{$\mathbf{F}$} & \multirow{2}{*}{ Sig. } & \multirow{2}{*}{$\mathbf{t}$} & \multirow{2}{*}{ df } & \multirow{2}{*}{$\begin{array}{l}\text { Sig. } \\
\text { (2- } \\
\text { tailed) }\end{array}$} & \multirow{2}{*}{$\begin{array}{l}\text { Mean } \\
\text { Difference }\end{array}$} & \multirow{2}{*}{$\begin{array}{l}\text { Std. } \\
\text { Error } \\
\text { Difference }\end{array}$} & \multicolumn{2}{|c|}{$\begin{array}{l}\text { 95\% Confidence Interval of the } \\
\text { Difference }\end{array}$} \\
\hline & & & & & & & & Lower & Upper \\
\hline Equal variances assumed &, 563 & ,457 & ,609 & 46 &, 546 & 9,58333 & 15,74436 & $-22,10842$ & 41,27509 \\
\hline Equal variances not assumed & & & 609 & 44,238 &, 546 & 9,58333 & 15,74436 & $-22,14253$ & 41,30920 \\
\hline
\end{tabular}

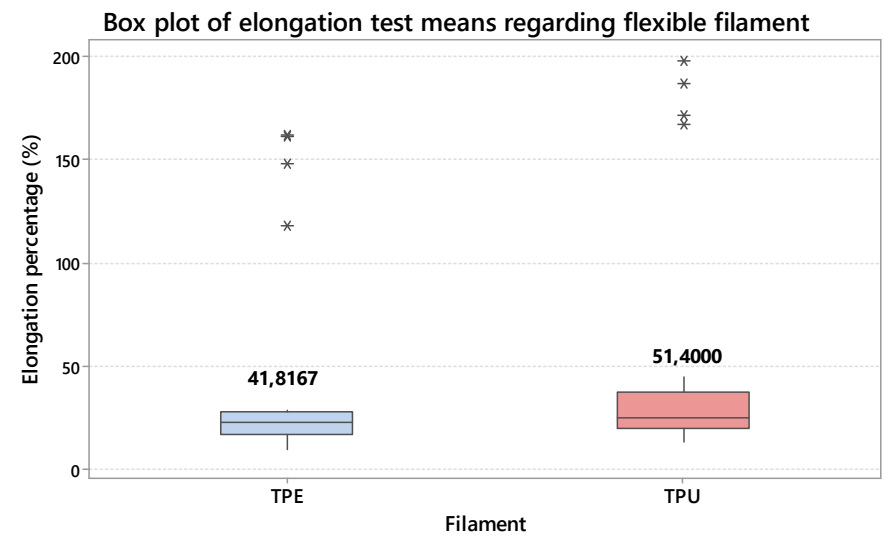

Fig. 33. Box Plot of Elongation Test Means Regarding Flexible Filament.

TABLE XI. DunCan's NeW Multiple Range Test For Elongation REGARDING PATTERN

\begin{tabular}{|c|l|l|l|}
\hline Duncan Group & Mean & N & Pattern \\
\hline A & 163.6000 & 8 & Snowflake - Line \\
\hline B & 30.7500 & 8 & Honeycomb - Line \\
\hline BC & 27.5500 & 8 & Honeycomb - Infill \\
\hline BC & 23.3875 & 8 & Flower of life - Line \\
\hline C & 18.3500 & 8 & Snowflake - Infill \\
\hline C & 16.0125 & 8 & Flower of life - Infill \\
\hline
\end{tabular}

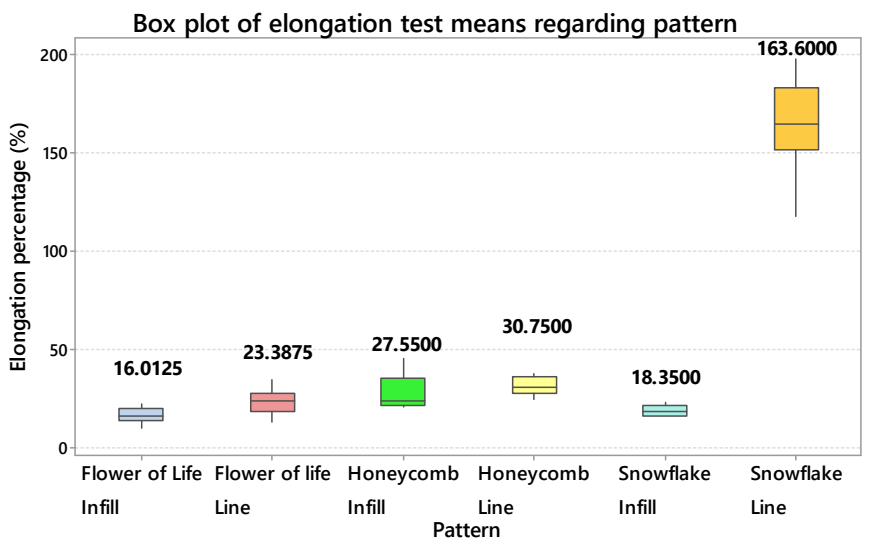

Fig. 34. Box Plot of Elongation Test Means Regarding Pattern. 
TABLE XIII. INDEPENDENT SAMPLES FOR ELONGATION TEST REGARDING 3D PRINTER

\begin{tabular}{|l|l|l|l|l|}
\hline 3D Printer & N & Mean & Std. Deviation & $\begin{array}{l}\text { Std. Error } \\
\text { Mean }\end{array}$ \\
\hline Anet A8 & 24 & 46,2417 & 52,59911 & 10,73675 \\
\hline M3D Crane Quad & 24 & 46,9750 & 56,83490 & 11,60138 \\
\hline
\end{tabular}

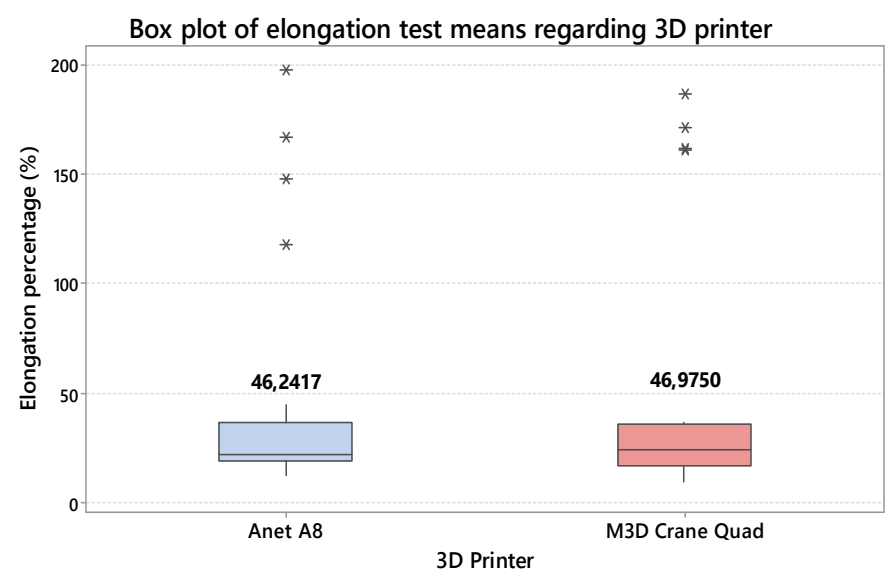

Fig. 35. Box Plot of Elongation Test Means Regarding 3D Printer.

3D Printer. Table XVI show the T-test results $(\mathrm{P} \geq 0$. 710) for the elongation test among $3 \mathrm{D}$ printers. It can be concluded that there is no significant difference between the Anet A8 printer and the M3D Crane Quad printer (see Table XIII and Fig. 35).

\section{B. Tensile}

Table XIV shows the data obtained during the tensile test. The test was performed to estimate the amount of force $(\mathrm{N})$ that can be applied to the pattern.

Table XV presents the ANOVA test results, showing that the design is significant and applicable for the two factors: flexible filament and pattern (see fig 36).

Filament factor (A). - The F-value $=15.110$ leaves a $\mathrm{p}$ value of 0.000 on the right, less than the $5 \%$ significance level. The effectiveness depends on the effect of the filament factor, which is significant; therefore, the design is effective, and the addition is successful. Thus, the tensile test depends on the filament factor when elaborating the garment.

Pattern factor (B). - The F-value $=43.429$, leaves a p-value of 0.000 , less than the $5 \%$ significance level. It means that some pattern significantly influences on the garment design. In other words, there are significant differences between patterns.

A $x$ B. - This row refers to the influence of all interactions between factors. The F-value $=0.758$ leaves a p-value of 0.586 , which is a not significant result. It must be concluded that there is no interaction between filament and pattern.

Error. - This row refers to the variance of the dependent variable not explained by the design.

Total. - This row shows the variance observed in the dependent variable caused by all the factors.

TABlE XIV. Data of Tensile StRength Test

\begin{tabular}{|c|c|c|c|c|c|}
\hline \multirow{3}{*}{ Filament } & \multirow{3}{*}{ Pattern } & \multicolumn{4}{|c|}{ 3D Print } \\
\hline & & \multicolumn{2}{|c|}{ A8 Anet } & \multicolumn{2}{|c|}{$\begin{array}{l}\text { M3D Crane } \\
\text { Quad }\end{array}$} \\
\hline & & $P 1$ & $\boldsymbol{P 2}$ & $P 1$ & P2 \\
\hline \multirow{6}{*}{ TPU } & Snowflake Line & 34.70 & 45.23 & 29.09 & 41.20 \\
\hline & Snowflake Infill & 50.50 & 55.36 & 48.27 & 54.37 \\
\hline & Flower of Life Line & 72.23 & 79.86 & 62.62 & 83.77 \\
\hline & Flower of Life Infill & 169.43 & 140.11 & 165.67 & 146.12 \\
\hline & Honeycomb Line & 64.40 & 94.29 & 28.77 & 102.13 \\
\hline & Honeycomb Infill & 98.28 & 62.08 & 61.76 & 58.54 \\
\hline \multirow{6}{*}{ ТPE } & Snowflake Line & 27.14 & 31.32 & 21.34 & 26.82 \\
\hline & Snowflake Infill & 44.94 & 50.45 & 38.06 & 34.44 \\
\hline & Flower of Life Line & 42.59 & 30.18 & 37.89 & 30.88 \\
\hline & Flower of Life Infill & 141.86 & 142.03 & 139.69 & 139.96 \\
\hline & Honeycomb Line & 22.04 & 76.81 & 41.35 & 63.70 \\
\hline & Honeycomb Infill & 86.07 & 18.51 & 68.50 & 17.77 \\
\hline
\end{tabular}

TABLE XV. ANOVA Results of TEnsile StRength TEst

\begin{tabular}{|l|l|l|l|l|l|}
\hline Source & df & $\begin{array}{l}\text { Sum of } \\
\text { Squares }\end{array}$ & $\begin{array}{l}\text { Mean } \\
\text { Square }\end{array}$ & F & Sig. \\
\hline Filamento (A) & 1 & 4693.201 & 4693.201 & 15.110 & 0.000 \\
\hline Patron (B) & 5 & 67447.163 & 13489.433 & 43.429 & 0.000 \\
\hline A x B & 5 & 1177.018 & 235.404 & 0.758 & 0.586 \\
\hline Error & 36 & 11181.991 & 310.611 & & \\
\hline Total & 47 & 84499.373 & & & \\
\hline
\end{tabular}

TABLE XVI. Results of T-Test For the ElONGATION TeSt REgARDing 3D PRINTER

\begin{tabular}{|l|l|l|l|l|l|l|l|l|l|}
\hline \multirow{2}{*}{} & \multicolumn{2}{|l|}{$\begin{array}{l}\text { Levene's Test for } \\
\text { Equality of Variances }\end{array}$} & \multicolumn{2}{l|}{ T-test for Equality of Means } \\
\cline { 2 - 10 } & F & Sig. & t & df & $\begin{array}{l}\text { Sig. } \\
\mathbf{2}- \\
\text { tailed) }\end{array}$ & $\begin{array}{l}\text { Mean } \\
\text { Difference }\end{array}$ & $\begin{array}{l}\text { Std. } \\
\text { Error } \\
\text { Difference }\end{array}$ & \multicolumn{2}{l|}{$\begin{array}{l}\text { 95\% Confidence Interval of the } \\
\text { Difference }\end{array}$} \\
\hline Lqual variances assumed &, 140 &, 710 &,- 046 & 46 &, 963 &,- 73333 & 15,80727 & $-32,55171$ \\
\hline $\begin{array}{l}\text { Equal variances not } \\
\text { assumed }\end{array}$ & & &,- 046 & 45,727 &, 963 &,- 73333 & 15,80727 & $-32,55684$ \\
\hline
\end{tabular}




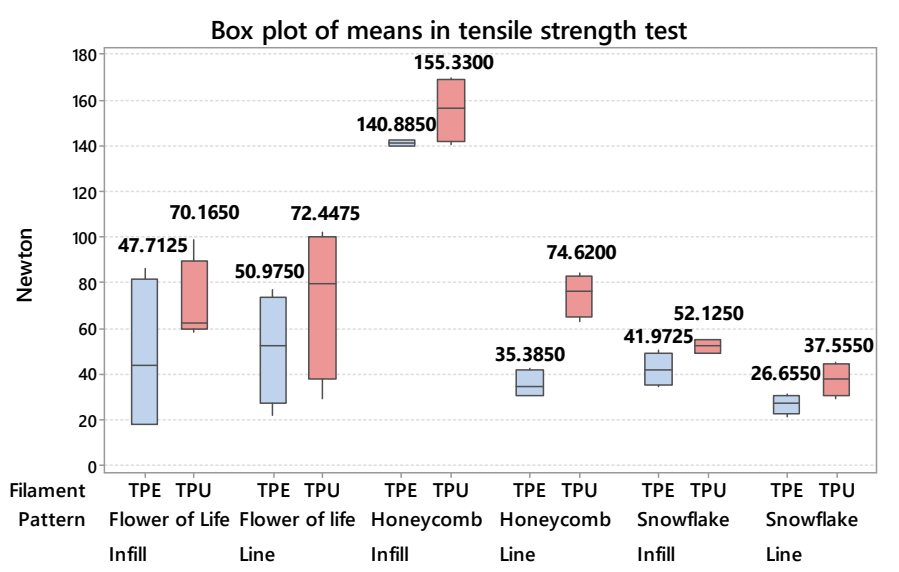

Fig. 36. Box Plot of Tensile Strength Test Means Regarding Pattern and Flexible Filament.

However, the ANOVA does not determine which treatment has the most significant average increase. A T-test was performed between flexible filament (A) and pattern(B) to find the mentioned value.

Flexible Filament (A). Table XIX show the results of the Ttest $(\mathrm{P} \geq 0.869)$. There is no statistical difference between the TPU and TPE filament during the tensile test (see Table XVII and Fig. 37).

TABLE XVII. INDEPENDENT SAMPLES FOR TENSILE TEST REgARDING FLEXIBLE FILAMENT

\begin{tabular}{|l|l|l|l|l|}
\hline Filament & N & Mean & $\begin{array}{l}\text { Std. } \\
\text { Deviation }\end{array}$ & Std. Error Mean \\
\hline TPU & 24 & 77,0404 & 41,17318 & 8,40444 \\
\hline TPE & 24 & 57,2642 & 42,12603 & 8,59894 \\
\hline
\end{tabular}

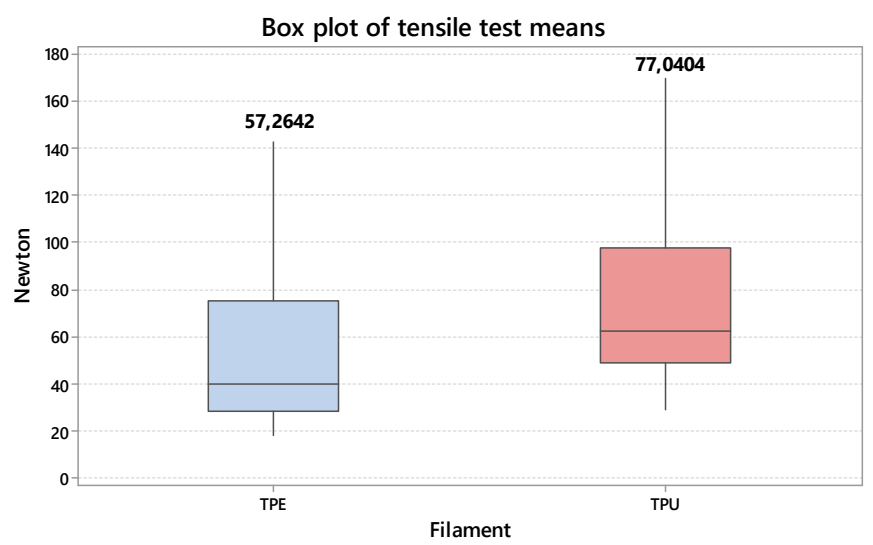

Fig. 37. Box Plot of Tensile Test Means.

Pattern (B). Table XVIII and Fig. 38 show the results of Duncan's new multiple range test $(\mathrm{P} \leq 0.05)$. It shows exemplars' performance for the Tensile test where the Honeycomb pattern - Infill (148.1075 N.) has a higher average score, indicating that it is statistically different from other designs.

TABLE XVIII. DunCan's NeW Multiple Range Test For the TENSILE TEST REgarding PATTERN

\begin{tabular}{|c|c|c|c|}
\hline Duncan Group & Mean & $\mathbf{N}$ & Pattern \\
\hline A & 148.1075 & 8 & Honeycomb - Infill \\
\hline B & 61.7113 & 8 & Flower of life - Line \\
\hline B & 58.9387 & 8 & Flower of life - Infill \\
\hline B & 55.0025 & 8 & Honeycomb - Line \\
\hline $\mathrm{BC}$ & 47.0487 & 8 & Snowflake - Infill \\
\hline $\mathrm{C}$ & 32.1050 & 8 & Snowflake - Line \\
\hline
\end{tabular}

TABLE XIX. Results of T-Test for the TEnsile Test Regarding FleXIBLE FILAMENT

\begin{tabular}{|l|l|l|l|l|l|l|l|l|l|}
\hline \multirow{2}{*}{} & \multicolumn{2}{|l|}{$\begin{array}{l}\text { Levene's Test for } \\
\text { Equality of Variances }\end{array}$} & \multicolumn{2}{l|}{ T-test for Equality of Means } \\
\cline { 2 - 10 } & F & Sig. & t & df & $\begin{array}{l}\text { Sig. } \\
\text { (2- } \\
\text { tailed) }\end{array}$ & $\begin{array}{l}\text { Mean } \\
\text { Difference }\end{array}$ & $\begin{array}{l}\text { Std. Error } \\
\text { Difference }\end{array}$ & $\begin{array}{l}\text { 95\% Confidence Interval of the } \\
\text { Difference }\end{array}$ & Lower \\
\hline Equal variances assumed &, 027 &, 869 & 1,645 & 46 &, 107 & 19,77625 & 12,02399 & $-4,42679$ & Upper \\
\hline $\begin{array}{l}\text { Equal variances not } \\
\text { assumed }\end{array}$ & & & 1,645 & 45,976 &, 107 & 19,77625 & 12,02399 & $-4,42713$ \\
\hline
\end{tabular}

TABLE XX. Results of T-Test For the Tensile Test REgarding 3D PRINTER

\begin{tabular}{|c|c|c|c|c|c|c|c|c|c|}
\hline & \multicolumn{2}{|c|}{$\begin{array}{l}\text { Levene's Test for } \\
\text { Equality of Variances }\end{array}$} & \multicolumn{7}{|c|}{ T-test for Equality of Means } \\
\hline & \multirow{2}{*}{$\mathbf{F}$} & \multirow{2}{*}{ Sig. } & \multirow{2}{*}{$\mathbf{t}$} & \multirow{2}{*}{ df } & \multirow{2}{*}{$\begin{array}{l}\text { Sig. } \\
(2- \\
\text { tailed) }\end{array}$} & \multirow{2}{*}{$\begin{array}{l}\text { Mean } \\
\text { Difference }\end{array}$} & \multirow{2}{*}{$\begin{array}{l}\text { Std. } \\
\text { Error } \\
\text { Difference }\end{array}$} & \multicolumn{2}{|c|}{$\begin{array}{l}\text { 95\% Confidence Interval of the } \\
\text { Difference }\end{array}$} \\
\hline & & & & & & & & Lower & Upper \\
\hline Equal variances assumed & ,031 & ,864 &,- 208 & 14 & ,838 & $-1,34500$ & 6,46151 & $-15,20356$ & 12,51356 \\
\hline $\begin{array}{l}\text { Equal variances not } \\
\text { assumed }\end{array}$ & & &,- 208 & 13,620 & ,838 & $-1,34500$ & 6,46151 & $-15,23993$ & 12,54993 \\
\hline
\end{tabular}




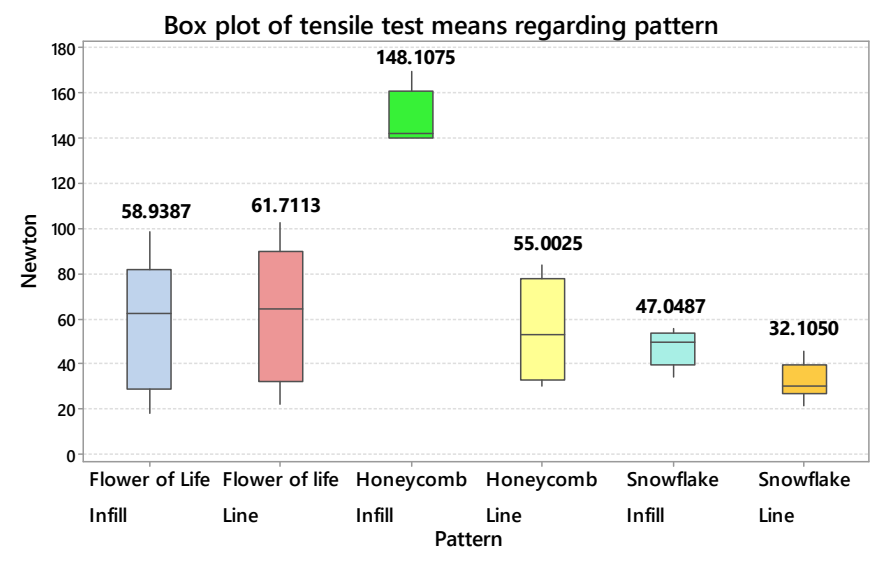

Fig. 38. Box Plot of Tensile Test Means Regarding Pattern.

3D Printer. Table XX show the T-test results $(\mathrm{P} \geq 0.864)$ for the tensile test among $3 \mathrm{D}$ printers. It can be concluded that there is no significant difference between the Anet A8 printer and the M3D Crane Quad printer (see Table XXI and Fig. 39).

TABLE XXI. INDEPENDENT SAMPLES FOR TENSILE TEST REgARDING 3D PRINTER

\begin{tabular}{|l|l|l|l|l|}
\hline 3D Printer & N & Mean & Std. Deviation & $\begin{array}{l}\text { Std. Error } \\
\text { Mean }\end{array}$ \\
\hline Anet A8 & 24 & 66,5575 & 44.82736 & 9.15035 \\
\hline M3D Crane Quad & 24 & 67,7471 & 40.78793 & 8.32580 \\
\hline
\end{tabular}

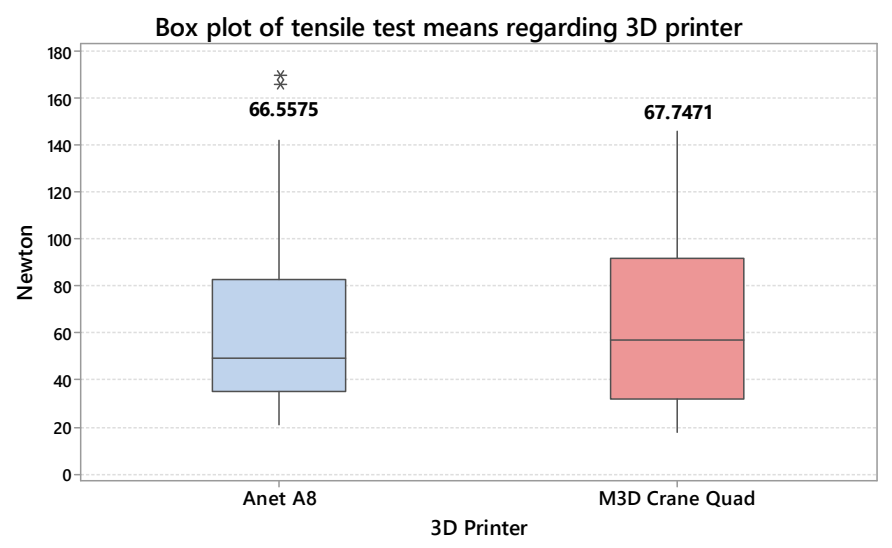

Fig. 39. Box Plot of Tensile Test Means Regarding 3D Printer.

\section{DISCUSSIONS}

The elongation and traction test were applied to the natural pattern and not to the garment composed of 29 pieces. It implies that the percentage of extending (elongation) and force applied to the garment itself until reaching the breaking point (tensile test) will have a higher performance.

The elongation test had greater importance when selecting the pattern to elaborate clothing since the elasticity property helps the garment adapt to different sizes (see Fig. 28, 29, 30, and 31).

In the thesis 3D Print Fashion [9], the author was inspired by a basic geometric figure pattern, among which octagons, hexagons, and triangles highlight. Although these patterns present characteristics similar to those of a mirror, the work does not evidence mechanical tests of tensile or elongation.

Danit [7] was inspired by Eugene Delacroix's "Liberty Leading The People" to select triangles' abstraction as a primary pattern. In the following experiments, Danit used Andreas Bastian's [30] cellular structure pattern; however, there is also no evidence of mechanical testing in his work.

In the work of 3D Print Fashion [9], the creation of a garment by digitalized fabrication of 3D printed surfaces was performed, which demonstrated that it is possible to create textile products with 3D printing technology. Besides, the mechanical design made possible the personalization of products. Such fact introduced the term "Customization" to the textile area.

On the other hand, Danit Peleg experimented with 3D printing, developing 3D manufactured garments. In her proposal for The Shenkar College of Engineering and Design in Israel, she demonstrated that it is possible to modify clothing after its initial design. Afterward, she designed complete collections and, by 2015, she began experimenting with customization [31].

\section{CONCLUSIONS}

Concerning the natural patterns proposed for this research and the percentage of elasticity, it is observed that there is significant variation among the results obtained in the elongation test. The Snowflake-line pattern is located in first place with an average value of $163.6 \%$ compared to the other designs. In Duncan's group, it was classified in section "A," with a higher value than the patterns organized in other sectors. This test's measurement is important because it states that the garment has the property of adaptability in the different sizes of women's clothing. However, the use of other patterns, especially line patterns, is not discouraged for the textile industry.

The tensile test shows that the honeycomb pattern with infill obtained the best performance (148.1075 N). However, the difference between the design with the best performance and the pattern with the lowest score is minor compared to the elongation test. In addition, data show that the patterns with infill variant achieved a better result since elasticity, which is an essential factor for the elaboration of the garment, has been removed.

Clothing printed with the M3D Crane Quad printer has slightly more elasticity. This statement can be observed in Fig. 29 and Fig. 31 since the garments are larger than those printed with the Anet A8 3D printer.

Lastly, with the flexible filament factor, no significant differences were observed when elaborating the garment's tensile tests. This fact presents that both filaments can be used for the elaboration of clothing.

\section{FUTURE WORK}

It is necessary to research the filament factor in 3D Printing, especially distinguishing the textile industry's flexible and rigid filaments since there is insufficient study. This proposal will help strengthen the line of research in 
Technology 4.0, Digital Manufacturing, and 3D Printing as a new textile research trend with the single purpose of developing textile products with filaments.

It is also essential to produce research that increases and improves 3D printing as an innovative knowledge. This approach can be conducted using other factors; filaments of different brands, time, cost, temperature, environment, climate, et al.

Lastly, more research is needed on clothing customization in 3D printing and pattern design, adding adaptability and comfort factors.

\section{REFERENCES}

[1] V. Betancur and F. Zuleta, 'Creación de una prenda mediante la fabricación digitalizada de superficies impresas en 3D', Iconofacto, vol. 13, no. 20, pp. 194-206, 2017, doi: 10.18566/iconofact.v13.n20.a11.

[2] J. Pérez De Lama Halcón, M. Gutiérrez De Rueda García, JM. SánchezLaulhé Sánchez De Cos, and JJ. Olmo Bordallo, 'Fabricación digital, código abierto e innovación distribuida’, 2012, [Online]. Available: http://hdl.handle.net/10251/15018.

[3] B. Mandelbrot, La geometría fractal de la naturaleza. 2014.

[4] D. Peleg, '3D Printed Fashion', 2017. https://danitpeleg.com/ (accessed Aug. 10, 2019).

[5] A. Jorquera, P. Coronel Romero, and P. I. Warren Alonso, Fabricación digital introducción al modelado e impresión 3D. Madrid: Ministerio de Educación, Cultura y Deporte, 2018.

[6] UNAJ, 'Líneas de Investigación de la Universidad Nacional de Juliaca', 2019. http://unaj.edu.pe/web2/?p=5904 (accessed Aug. 12, 2019).

[7] D. Peleg, '3D Printed Jacket', Danit Peleg. https://danitpeleg.com/product/create-your-own-3d-printed-jacket/ (accessed Jan. 30, 2020).

[8] D. Peleg, Fashion + 3D Printing, 2014. http://danitpeleg.com (accessed Sep. 06, 2019).

[9] V. Betancur Fernández, '3D Print Fashion: Creación de una prenda vestimentaria mediante la fabricación digitalizada de superficies impresas en 3D.', Tesis de pregrado, Universidad Pontificia Bolivariana, Medellín, Colombia, 2016.

[10] W. Wang, G. Zhang, L. Yang, and W. Wang, 'Research on garment pattern design based on fractal graphics', EURASIP J. Image Video Process., vol. 2019, no. 1, p. 29, Dec. 2019, doi: 10.1186/s13640-0190431-x.

[11] A. D. K.-T. Lam, 'A study on fractal patterns for the textile design of the fashion design', in 2017 International Conference on Applied System Innovation (ICASI), Sapporo, Japan, May 2017, pp. 676-678, doi: 10.1109/ICASI.2017.7988605.

[12] D. Halápi, S. E. Kovács, Z. Bodnár, Á. B. Palotás, and L. Varga, 'Tensile analysis of 3D printer filaments', presented at the MultiScience - XXXII. microCAD International Multidisciplinary Scientific Conference, 2018, doi: 10.26649/musci.2018.013.

[13] D. Stechina, S. M. Mendoza, H. D. Martín, C. N. Maggi, and M. T. Piovan, 'Determinación de propiedades elásticas de piezas poliméricas construidas por impresión 3D, sometidas a flexión', Matér. Rio Jan., vol. 25, no. 2, p. e-12617, 2020, doi: 10.1590/s1517707620200002.1017.

[14] L. Alvarez C, R. F. Lagos C, and M. Aizpun, 'Influencia del porcentaje de relleno en la resistencia mecánica en impresión 3D, por medio del método de Modelado por Deposición Fundida (FDM)', Ingeniare Rev. Chil. Ing., vol. 24, no. Especial, pp. 17-24, Aug. 2016, doi: 10.4067/S0718-33052016000500003.

[15] N. G. Tanikella, B. Wittbrodt, and J. M. Pearce, 'Tensile strength of commercial polymer materials for fused filament fabrication 3D printing', Addit. Manuf., vol. 15, pp. 40-47, May 2017, doi: 10.1016/j.addma.2017.03.005.

[16] D. Chakerian and B. B. Mandelbrot, 'The Fractal Geometry of Nature', Coll. Math. J., vol. 15, no. 2, p. 175, Mar. 1984, doi: 10.2307/2686529.

[17] P. Valdés, 'Introducción a la geometría fractal', Tesis de pregrado, Universidad del Bío-Bío, Chillán, Chile, 2016.

[18] A. I. Ramírez-Galarza, Geometría analítica: una introducción a la geometría. México: UNAM, Facultad de Ciencias, Coordinacion de Servicios Editoriales, 2013.

[19] J. Garcá, Fractales. Salamanca: Facultad de Bellas Artes, 2014.

[20] B. B. Mandelbrot and J. Llosa, La Geometría fractal de la naturaleza. Barcelona: Tusquets, 2003.

[21] V. Arguedas T., 'La Geometría de la Naturaleza: Benoit Mandelbrot', Rev. Digit. Matemática Educ. E Internet, vol. 12, no. 1, Mar. 2014, doi: 10.18845/rdmei.v12i1.1685.

[22] A. Amadio, 'La Naturaleza Fractal', Rev. Argent. Psicopedag. ISSN 1514-5603 N 58 2004, Jan. 2004.

[23] W. D. Browning, C. O. Ryan, and J. O. Clancy, 14 Patrones de diseño biofilico. New York: Terrapin Bright Green, LLC, 2017.

[24] P. Munro, 'Fractals For Fashion - Textile Weaving Designs', Fibre2fashion, 2010. http://www.fibre2fashion.com/industryarticle/4999/fractals-for-fashion-textile-weaving-designs (accessed Aug. 20, 2020).

[25] F. Hernandez, P. Palominos, M. Orellana, and M. Ochoa, 'Fractals and their contribution to the design of textile prints', vol. 109, pp. 47-57, Jan. 1996.

[26] J. F. Francolí and R. B. Díaz, 'Estado actual y perspectivas de la impresión en 3D’, Artíc. Econ. Ind., p. 15, 2014.

[27] F. Bordignon, A. A. Iglesias, and Á. Hahn, Diseño e impresión de objetos 3D: una guía de apoyo a escuelas, 1ra. ed. Buenos Aires: Universitaria, 2018.

[28] F. Leyton, 'Estudio y caracterización de las variables que afectan a la impresión 3D en la generación de objetos manipulables’, Investigación, Universidad de la República, Montevideo, Uruguay, 2016.

[29] O. A. Herrera and M. Figueroa, 'Impresión 3d de proyectos de ingeniería y construcción', Tesis de pregrado, Universidad Andrés Bello, Santiago, Chile, 2017.

[30] A. Bastian, 'Mesostructured Cellular Materials: Early Prototypes', Makerbot Thingiverse, 2014. https://www.thingiverse.com/thing:289650 (accessed Jan. 30, 2020).

[31] 'Danit Peleg', Wikipedia, la enciclopedia libre. Dec. 20, 2020, Accessed: Feb. 20, 2021. [Online]. Available: https://es.wikipedia.org/w/index.php?title=Danit_Peleg\&oldid=1318362 99. 